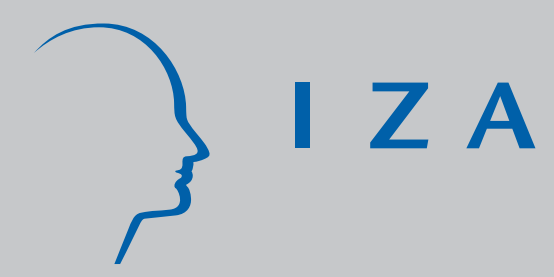

IZA DP No. 3609

Cognitive Skills Explain Economic Preferences, Strategic Behavior, and J ob Attachment

\author{
Stephen V. Burks \\ J effrey P. Carpenter \\ Lorenz Götte \\ Aldo Rustichini \\ J uly 2008
}




\title{
Cognitive Skills Explain Economic Preferences, Strategic Behavior, and Job Attachment
}

\author{
Stephen V. Burks \\ University of Minnesota, Morris and IZA \\ Jeffrey P. Carpenter \\ Middlebury College and IZA \\ Lorenz Götte \\ Federal Reserve Bank of Boston and IZA
}

Aldo Rustichini

University of Minnesota

Discussion Paper No. 3609
July 2008

IZA

P.O. Box 7240

53072 Bonn

Germany

Phone: +49-228-3894-0
Fax: +49-228-3894-180
E-mail: iza@iza.org

Any opinions expressed here are those of the author(s) and not those of IZA. Research published in this series may include views on policy, but the institute itself takes no institutional policy positions.

The Institute for the Study of Labor (IZA) in Bonn is a local and virtual international research center and a place of communication between science, politics and business. IZA is an independent nonprofit organization supported by Deutsche Post World Net. The center is associated with the University of Bonn and offers a stimulating research environment through its international network, workshops and conferences, data service, project support, research visits and doctoral program. IZA engages in (i) original and internationally competitive research in all fields of labor economics, (ii) development of policy concepts, and (iii) dissemination of research results and concepts to the interested public.

IZA Discussion Papers often represent preliminary work and are circulated to encourage discussion. Citation of such a paper should account for its provisional character. A revised version may be available directly from the author. 


\title{
ABSTRACT \\ Cognitive Skills Explain Economic Preferences, Strategic Behavior and Job Attachment
}

\begin{abstract}
Economic analysis has said little about how an individual's cognitive skills (CS's) are related to the individual's preferences in different choice domains, such as risk-taking or saving, and how preferences in different domains are related to each other. Using a sample of 1,000 trainee truckers we report three findings. First, we show a strong and significant relationship between an individual's cognitive skills and preferences, and between the preferences in different choice domains. The latter relationship may be counterintuitive: a patient individual, more inclined to save, is also more willing to take calculated risks. A second finding is that measures of cognitive skill predict social awareness and choices in a sequential Prisoner's Dilemma game. Subjects with higher CS's more accurately forecast others' behavior, and differentiate their behavior depending on the first mover's choice, returning higher amount for a higher transfer, and lower for a lower one. After controlling for investment motives, subjects with higher CS's also cooperate more as first movers. A third finding concerns on-the-job choices. Our subjects incur a significant financial debt for their training that is forgiven only after twelve months of service. Yet over half leave within the first year, and cognitive skills are also strong predictors of who exits too early, stronger than any other social, economic and personality measure in our data. These results suggest that cognitive skills affect the economic lives of individuals, by systematically changing preferences and choices in a way that favors the economic success of individuals with higher cognitive skills.
\end{abstract}

JEL Classification: $\quad$ C81, C93, L92, J63

Keywords: field experiment, risk aversion, ambiguity aversion, loss aversion, time preference, Prisoners Dilemma, social dilemma, IQ, MPQ, numeracy, U.S. trucking industry, for-hire carriage, truckload (TL), driver turnover, employment duration, survival model

Corresponding author:

Stephen V. Burks

Division of Social Science

University of Minnesota Morris

600 East 4th Street

Morris, Minnesota 56267

USA

E-mail: svburks@morris.umn.edu 
Economic, financial, and real life decisions involve options that vary along several distinct dimensions, such as the probability of the outcomes, or in the times at which the outcomes will be delivered. These factors affect the choices of different individuals differently; for example, some people are more prudent in risk-taking, while others are more patient in their choices of saving versus consumption. Individuals also differ in their cognitive skills. Economic analysis has so far said little about the way the general cognitive skills of an individual might be related to that individual's economic preferences, and about whether and how the preferences of the same individual in different domains of choice, such as risk-taking or saving, might be related to each other (1-4). Psychologists have studied the relationship between various cognitive skills and job success, among other outcome variables, but without focusing on the link between cognitive skills and preferences (5). Similarly, little is known about how cognitive skills influence behavior in strategic interactions. But an understanding of the effects cognitive skills may have on preferences (6) and strategic behavior, and the relations that may exist among preferences, is of considerable potential importance in constructing theories of human decision-making and in selecting managerial and public policies.

We examine whether and how cognitive skills are related to attitudes towards risk, ambiguous probability, and inter-temporal choices, and how choices in these distinct domains are related to each other in a large sample $(\mathrm{N}=1066)$ of trainee tractor-trailer drivers at a sizable U.S. trucking company (see supporting online material (SM) and (7)). We also examine how cognitive skills are related to two types of behavior by these subjects: laboratory choices in a strategic game, and an important on-the-job decision. In each case we are able to control for potentially confounding socio-economic and psychological factors. Our results are enabled by a comprehensive data collection design, which gives the opportunity to observe socio-economic, demographic, psychological, experiment-based, and employment-related outcome variables for the same subjects.

We collected three measures of cognitive skills (CS's): a non-verbal IQ test (Raven's matrices), a quantitative literacy (or "numeracy") test and a test of the ability to plan (referred to as the "Hit 15" task). To measure risk preferences we used an experiment in which subjects chose between various fixed payments and a lottery, and for ambiguity subjects faced the same choices as in the risk experiment, but were given incomplete information about the probability of outcomes (8). Time preferences are measured from an experiment in which subjects chose between earlier but smaller payments and later but larger ones. Our laboratory behavioral measure of strategic behavior is from a sequential form of the Prisoner's Dilemma: a first mover chooses whether to send $\$ 0$ or $\$ 5$ to a second mover, and the latter in turn decides how much to send back. In both instances the amount sent were doubled by the experimenter. Subjects stated their choices in both roles, and their beliefs about the moves of others.

Our on-the-job measure of behavior results from our access to internal human resource data maintained by the firm: in a high-turnover setting, we observe the length of time each subject remained with the company, and the reason for leaving.

We also collected a demographic and socio-economic profile and a standard personality questionnaire from each subject. Details of the experimental design and implementation are presented in the Methods section (see also SM and (7)).

\section{Results}

\section{Choice Consistency and CS's}

If choice requires information processing, then a simple hypothesis about cognitive skills and preferences is that those with higher cognitive skills should make fewer errors in translating their preferences into choices. This is confirmed by examining variations in choice consistency among our subjects: In our risky and ambiguous choices the lottery is fixed, so as the value of the certain amount increases in different choices, subjects who are transitive and prefer more money to less should switch at most once between the lottery 
and the certain amount. A very risk averse or risk seeking subject may never switch, but switching more than once shows inconsistency in choice. The same applies to choices over earlier versus later payment times: the future payment is fixed, so as the value of the early payment decreases, subjects should switch at most once.

The effect of CS's on consistency is large (Figure $1 \mathrm{~A}$ ): a change from the lowest to the highest quartile in the IQ index increases the likelihood of being consistent by about $25 \%$ in risky choice, and by about $18 \%$ in ambiguous choices (10). In choices over time the probability of consistency increases by about 15\%. The results are confirmed by a multivariate logit estimate (SM, 9, 10, 11).

\section{CS's and Economic Preferences: Theory}

We have seen that CS's affect the consistency of choices: they may directly affect the content of economic preferences. How might such an effect occur? Observe that one may think of perceived utility as noisy. One may model (12) perception of utility as the observation of a random variable equal to the true utility plus noise. The more complex is the option, the larger is the noise. The utilities of simple options-such as a sure payment of \$10-are perceived precisely. But a lottery-two possible outcomes with an expected value of $\$ 10-$ is complex. Its utility is harder to evaluate, and so is noisy. Similarly, $\$ 10$ paid immediately is simple, and its utility is clear, whereas $\$ 10$ to be paid in two weeks is complex-multiple factors could intervene-and its utility is noisy.

This difference in perception may systematically affect choices. If evaluating the overall utility of a complex option is harder for a subject, he may focus on some specific aspect of it, which could guide his choice: of the two outcomes of $\$ 2$ and $\$ 10$ in our lottery he may focus on the lower (if pessimistic), or on the higher (if optimistic). Subjects who find a more comprehensive evaluation easier will be more likely to focus on the average value. This systematic effect may have deep roots: an implication of several models of the decision process, such as the random walk model (13-15), is that, other things equal, an option which is perceived more noisily is less likely to be chosen than one perceived more precisely.

We hypothesize that higher cognitive skills are associated with less noise in the perception of the utility of complex options. If this is correct, we should observe a higher concentration of choices near the expected value from subjects with higher level of CS's, and among those with lower values we should observe the effects of pessimism or optimism, particularly in evaluating gains and losses, and of the simplification of options. In these cases, the effect of psychological traits, such as harm avoidance, may become relevant.

\section{CS's and Economic Preferences: Evidence}

A measure of risk aversion is the coefficient of risk aversion in the Constant Relative Risk Aversion (CRRA) specification: a higher coefficient corresponds to higher risk aversion. This measure indicates that subjects with lower IQ are less willing to take risks when the outcomes are positive (Fig. 1B). Its value is on average around 0.8 for the lowest IQ quartile, and less than 0.4 for the highest one. Risk aversion depends on the stakes, and is stronger with higher stakes (16). The increase in risk aversion from low to higher stakes also depends on CS's, and is smaller in subjects with higher CS's (SM). This smaller difference in risk aversion levels across choices in different ranges of outcomes can be seen as another way that choice consistency increases with CS's. The relationship between CS and attitudes to risk changes qualitatively with losses. Subjects with lower CS (who are more risk averse when gains are at stake) become more risk seeking in the domain of losses than subjects who have higher CS's (Figure 2, C and D).

A possible confound is that cognitive skills may affect choices involving money indirectly, through affecting the income available to individuals. Our data permit us to statistically control for the effect of variables such as education, alternative income, and credit score, and we find that the significance and importance of the effects of the IQ index 
and numeracy on risk-taking are robust to the inclusion of such controls. The same holds if we introduce psychological personality traits, such as harm avoidance (see SM).

Subjects in higher percentiles of the IQ index are more patient (Fig. 1, C and D). The increase in patience associated with increasing IQ is similar over the four choice sets, two of which include an immediate payment, and two do not. Impulsivity is likely to affect only the two choice sets in which today is an option. So the effect of CS's is significant even when none of the payments is immediate. This evidence cuts against the view that higher CS's increase patience through the control of impulsivity.

Broadly, for lotteries with positive outcomes the willingness to take calculated risks and patience both increase with the level of CS's. However, the relationship is not monotonic (Fig. 2, D and D). The IQ index reaches the highest average value in subjects just below risk neutrality, and then falls slightly. The same occurs for time preferences.

The effects of cognitive skill on preferences are substantial. The average IQ among those who always prefer the sure payment is one standard deviation below those who behave in a risk-neutral way. The implied premium someone in the bottom third in IQ would pay for full insurance (at our modest lottery stakes levels) is 7.5 per cent, as against 2.3 per cent for the top third. The bottom third requires an implicit interest rate between 20 and 37 percent higher to save than does the top third.

\section{Relationships among Economic Preferences}

Since willingness to take risks and patience both increase with cognitive skills, they should be positively correlated, and indeed the correlation coefficients for simple statistics of choice show that they are. We compute the correlation among the number of times the subject chooses the risky lottery (an indicator of risk propensity), the number of times the subject chooses the later payment (an indicator of patience), and the IQ index (see SM). The latter index has a strong and significant correlation with all the choices.

Cross correlations among preferences expressed through different choices in the same domain (for example choices over time for different time horizons) are strong and significant. Also choices under risk and over time are correlated, particularly among choices with positive outcomes and a short time horizon. The single important exception in this table is represented by the two lotteries with negative outcomes. For the lottery $(\$ 5,-\$ 1)$ the pair-wise correlation with the IQ index is insignificant, and for the lottery $(\$ 1,-$ $\$ 5$ ) it is significant and negative (17).

The study of the correlation between attitudes towards risk and ambiguity requires a careful separation of the two factors: a risk adverse individual who is not ambiguity averse would exhibit perfect correlation of choices in risk and ambiguity. The degree of risk aversion is measured by the way utility varies with different amounts of money, while that of ambiguity aversion is measured by how strongly the choice is influenced by the lack of precision in the probability of outcomes. When we separate the two factors, risk aversion and ambiguity aversion are strongly and significantly positively correlated (see SM).

\section{CS's and Strategic Choices}

Overall subjects with higher levels of cognitive skills are better able to anticipate the behavior of others in our sequential Prisoner's Dilemma game. 67\% of the subjects chose to send $\$ 5$ as first mover, while the average belief was $50.2 \%$. Subjects with higher IQ more accurately predicted first mover behavior, with almost a 28\% increase over the entire range of the index (18). The same holds for the prediction of return transfers by the second mover after a \$5 transfer: an increase in the IQ index increases the value of the transfer predicted by the subject, and the distance between the true value and the predicted value decreases with higher IQ and numeracy scores (see SM). The exception is the prediction of the average amount returned after a $\$ 0$ transfer. In this case, the distance between estimate and reality increases with IQ and numeracy scores because subjects with higher scores expect that the transfer back in response to a $\$ 0$ first move will be lower than it is in reality. 
The differences associated with CS scores extend from beliefs to behavior (Figure 3). Subjects with higher IQ transfer a higher amount after a transfer of $\$ 5$, and a lower one after a transfer of $\$ 0$ (19). The behavior of the first mover is also affected: subjects with higher cognitive skills are more likely to send \$5. A potential confound is that subjects with higher CS's expect a higher return to sending $\$ 5$, and are more inclined to take risks, so sending $\$ 5$ might be more attractive them as a (purely) financial investment. After correcting for this factor, the IQ index is positively and systematically related to first mover sending, both as interacted with the expectation of a higher return, and also directly, controlling for the expectation difference (SM) (20).

\section{Job Attachment}

The previous results are based on abstract choices (e.g. lotteries) involving moderate amounts of money, made in a controlled laboratory environment, albeit a temporary one placed in a field setting. The external validity, i.e. the usefulness of such findings in predicting economic behavior outside the laboratory, is controversial. Our data permit us to test this relationship, and we find strong support for the external validity of our laboratory measures and experimental findings.

In large firms of the type we study, the American Trucking Associations consistently report that annual turnover rates exceed 100\% (21). Most driver trainees, including our subjects, borrow the cost of training from their new employer, a debt which is forgiven after twelve months of post-training service, but which becomes payable in full upon earlier exit. Yet over half our subjects exit before twelve months, which makes predicting survival of considerable interest.

Figure 4 displays the survival curves for distinct values of a typical socio-economic variable (marital status), as well as for each quintile for the Hit 15 Index. The difference between married and un-married is small, while the difference among the quintiles in any of the cognitive skills scores is large. Marital status is typical of other socio-economic variables, such as credit score, number of dependents, prior job, and so on: these explain little of the variation in survival. The survival curves are similar for the IQ Index and the Numeracy. The difference between survival levels at different scores is particularly large for the Hit 15 Index: the survival for the top scorers is twice as large as for the bottom ones.

These effects are robust to including various potentially confounding factors as statistical controls. A Cox proportional hazards regression including the three CS indices, several demographic and socio-economic variables (age, gender, previous experience, credit score, etc.) and indices of preferences derived in the experimental session (e.g. indices of risk and ambiguity aversion, and time preferences) shows that the variables with the largest and robustly significant effects are those measuring cognitive skill (see SM).

Considering different exit categories using the Cox proportional hazards model confirms that poor ability to plan is a key link between CS's and exits. Departing during initial training, but after the credit agreement can no longer be cancelled, is perhaps the strongest indication of a mismatch between the worker and the company that the student driver did not anticipate. The reduction of the risk of exit associated with a higher Hit15 Index is more than double for exits during initial training than it is for exits later, on the job (see SM).

There is a good reason for the size of the effect of cognitive skill factors, and especially Hit 15. This index measures the ability of the individual to effectively reason backwards from a goal about how to achieve it. Survival means trainees correctly anticipated their own performance in a new environment (the training school and the new job). But more specifically, truck driving for this type of firm requires the calculation each day of the current actions needed to achieve specific near-term goals under multiple and often conflicting constraints (22). In fact, drivers have to update the firm daily about this calculation over a satellite uplink in their truck. However, the value of this ability clearly applies beyond trucking, to any occupation requiring a significant amount of independent work. 
In a multivariate analysis, controlling for the effect of cognitive skills on exit risk, economic preferences also predict exit risk. In particular, when we separate voluntary quits (75\% of all exits) from discharges (25\%), we find that choosing a higher number of future payments in the time preferences experiment predicts a lower likelihood of quitting (SM) (23).

\section{Discussion}

Cognitive skills might affect choices in the same way they affect the ability to produce the sum of two numbers: higher skill can reduce the number of errors. We do in fact find that lower error rates are associated with higher levels of cognitive skills. But if this were the only way in which cognitive skills affect preferences, we should observe only a larger variance in the choices made by those with lower cognitive skills, and no systematic effects, just as we do not see a systematic effect on the sum in addition problems.

We have found that the relationship is deeper, and it may offer an explanation of economic success of individuals. Preferences of individuals differ systematically with cognitive skills: higher cognitive skills are associated with a larger willingness to take calculated risks and higher patience. As a consequence, patience and willingness to take risks are positively correlated. Cognitive skills are also associated with higher social awareness and a greater tendency to be cooperative, so if they influence economic success, it is not by producing blind selfishness. The effect is substantial, and goes well beyond laboratory measures: we have seen how it can significantly affect job tenure.

Economic theory has so far considered cognitive skills as extremely important variables, but they have only been treated as endowments that increase the set of feasible options for an individual. These results show that cognitive skills do something else: cutting across all domains of choice, they introduce systematic effects in, and correlations among, economic preferences.

The novel relationships we find have potentially deep implications. For example, Gregory Clark recently suggested that the initial location of the industrial revolution in England may have been due to a "survival of the richest" selection process, that operated there from as early as 1250 C.E. (24). This selection may have been cultural, genetic, or both. He suggests that selection favored "capitalist" traits that include several of the ones (e.g. risk taking and saving propensity) we analyze herein. Were these traits independent, it is hard to imagine how a selection process could induce such a bundled concentration in the time frame suggested. But if these traits are correlated due to their linkage with cognitive skills, then a "selection of the richest" explanation, operating through selection for cognitive skills, becomes more plausible (25).

Our findings are relevant for the development of better theories of human decision making, and change the way we look at important policy issues. Decisions about retirement involve using cognitive skills to simultaneously apply attitudes towards risk and to the allocation over time of future payments. Numerical skills are already known to significantly affect such decisions $(1,6)$, and our results generalize this finding. The same holds for a variety of problems in the areas of health insurance, health care, and investments in education, and in the area of labor contracts and employment choices. The relationships we find between cognitive skills and economic preferences, and among economic preferences, should be taken into account in designing improved decision theories, labor contracts, insurance policies, and related public policies.

\section{Methods}

\section{The Field Setting}

Our data was collected in a temporary laboratory set up in a company-operated training school, so that the social framing of the economic experiments was provided by the economic context of interest: training with a new employer for a new occupation. Over the 
course of a year we ran extensive experiments ( 4 hours per session) with the participating subjects, in groups ranging from 20 to 30 at a time.

\section{Measures of Cognitive Skills}

We collected three different measures of cognitive skills (CS's) (26). The first was a licensed subset of Raven's Standard Progressive Matrices (SPM) (27). The SPM is a measure of non-verbal IQ consisting of a series of pattern matching tasks that do not require mathematical or verbal skill.

The second was a section of a standard paper-and-pencil test for adults of quantitative literacy, or "numeracy," from the Educational Testing Service. Subjects read and interpreted text and diagrams containing numerical information, and did arithmetic calculations, such as computing percentages, based on that information (28).

The third instrument was a simple game, called Hit 15, played against the computer. This required reasoning backwards from the game's goal, which was to reach 15 total points from a varying initial number less than 15 , to which each player had to add between 1 and 3 points on each round (29).

\section{Measures of Economic Preferences}

In the experiment on risk preferences subjects made four sets of seven choices. The fixed payment increased in value with each choice, while the lottery was constant: a promise to pay the subject either a higher or a lower dollar amount, such as $\$ 10$ or $\$ 2$, depending on a random device which had a $50 \%$ probability for each outcome. Over the four sets of choices the amounts at stake varied between a gain of $\$ 10$ and a loss of $\$ 5$, so we could study the effects of stake size, and of losses as compared to gains. We identify preferences using the certainty equivalent method (30). The experiment on ambiguity was identical except that subjects knew less about the lotteries-only that each outcome had at least a $20 \%$ chance. Subjects were paid real money for one of the choices in each experiment, selected randomly.

In our experiment on time preferences subjects made four sets of six choices. The later payment was always $\$ 80$, while the earlier one ranged from $\$ 75$ to $\$ 45$, in increments of $\$ 5$. We offered time horizons from today to thirty days hence. The goal was to compare shorter time horizons to longer ones, plus capture any special features of immediacy, while ensuring subjects would be present at the field site at as many the payment dates as possible (31). Two subjects from each test group were randomly selected to receive payment on the date they had selected in one of the 24 choices, which was also selected at random.

\section{Social Dilemma Experiment}

Our version of the sequential Prisoner's Dilemma has a first mover and a second mover, and each subject chose actions both as a first and as a second mover. We randomly and anonymously paired subjects and randomly assigned their roles to determine payoffs.

Both the first and second mover were endowed with $\$ 5$, and asked if they wanted to send money to the other player: what was kept would be theirs at the end, and what was sent would be doubled by the experimenters before reaching the other player. The first mover made an unconditional choice to send either none of the endowment $(\$ 0)$ or all of it $(\$ 5)$. The second mover made two separate choices about returning between $\$ 0$ and $\$ 5$ (in dollar increments) from his endowment, one in case the first mover had sent $\$ 0$, and a second in case the first mover had sent $\$ 5$.

We also asked each subject what percentage of first movers would send $\$ 5$, and also what the average amount sent by second movers responding to $\$ 0$ and to $\$ 5$ transfers would be. We paid subjects extra if their estimates matched the actual behavior.

\section{Turnover in the firm}


The length of job tenure is a key indicator of economic success for both firm and driver-trainee. The firm has at stake its investment in recruiting and training (between $\$ 5,000$ and $\$ 10,000$ ) and its reputation in the labor market. The trainee has at stake the debt for driver training (which is cancelled after 12 months of service, but becomes immediately payable in full upon earlier exit), his job record, and his credit history. To address external validity we examine what affects the survival curve, which is an estimate of the proportion of the initial trainee population remaining at each tenure-length that takes into account the inflow of trainees over time and the right-censoring of incomplete tenure spells (31).

\section{Acknowledgements}

The authors gratefully acknowledge generous financial support for the Truckers and Turnover Project from the John D. and Catherine T. MacArthur Foundation's Research Network on the Nature and Origin of Preferences, the Alfred P. Sloan Foundation, the Trucking Industry Program at the Georgia Institute of Technology, the University of Minnesota, Morris, the Federal Reserve Bank of Boston, and financial and in-kind support from the cooperating motor carrier, its staff, and its executives. The views expressed are those of the authors, and do not necessarily reflect the views of any of their employers nor of the project's funders. Authors are listed in alphabetical order; Burks is the project organizer. 
Notes and References

1. Banks J \& Oldfield Z (2007) Understanding Pensions: Cognitive Function, Numerical Ability and Retirement Saving. Fisc. Stud. 28, 143-170.

2. Borghans L, Duckworth AL, Heckman JJ, Weel B, The Economics and Psychology of Personality Traits, NBER WP 13810

3. Bowles S, Gintis H, \& Osborne M (2001) The Determinants of Earnings: A Behavioral Approach. J. Econ. Lit., 1137-1176.

4. Eckel C, Johnson C, \& Montmarquette C (2005) Saving Decisions of the Working Poor: Short- and Long-Term Horizons. Res. Exp. Econ. 10.

5. Neisser U, Boodoo G, Bouchard TJ, Jr., Boykin AW, Brody N, et al. (1996) Intelligence: Knowns and unknowns. Am. Psych. 51, 77-101.

6. Peters E, Västfjäll D, Slovic P, Mertz CK, Mazzocco K, et al. (2006) Numeracy and Decision Making. Psych. Sci. 17, 407-413.

7. Burks S, Carpenter J, Götte L, Monaco K, Porter K, et al. (2008) in The Analysis of Firms and Employees: Quantitative and Qualitative Approaches, eds. Bender S, Lane J, Shaw K, Andersson F, \& von Wachter T (NBER and University of Chicago ).

8. The lottery device was a bowl with green and blue chips. Subjects selected which color gave them the larger payment after the chips had been put into the bowl, so they knew that the color proportions could not be biased for or against them.

9. IQ and numeracy are both normalized to a $[0,1]$ interval. Results in this paragraph exceed any conventional threshold of statistical significance. Numeracy: 26\% Marginal Effect (ME), at significance level $p=0.0001 ;$ IQ: $23 \% \mathrm{ME}$ at $\mathrm{p}=0.012$.

10. Numeracy: $18 \% \mathrm{ME}$ at $\mathrm{p}=0.0001 ; \mathrm{IQ}: 18 \% \mathrm{ME}$, at $\mathrm{p}=0.008$.

11. Numeracy: $18 \%$ ME at $\mathrm{p}=0.0001$; IQ: $15 \% \mathrm{ME}$, at $\mathrm{p}=0.006$.

12. Rustichini A (2008) in Neuroeconomics: Decision making and the Brain, eds. Glimcher et al.

13. Ratcliff R (1978) A Theory of Memory Retrieval. Psych. Rev. 85, 59-108.

14. Shadlen MN \& Newsome WT (1996) Motion perception: seeing and deciding. Proc. Natl. Acad. Sci. USA 93, 628-633.

15. Shadlen MN \& Newsome WT (2001) Neural basis of a perceptual decision in the parietal cortex (Area LIP) of the rhesus monkey. Jnl. Neurophys. 86, 1916-1936.

16. Friedman M \& Savage L (1948) The Utility Analysis of Choices involving Risk. J. Polit. Economy 56, 279-304.

17. The special role of the lotteries with negative outcomes is confirmed by the factor analysis of choices (see SM) which shows that lotteries with negative outcomes (especially $(\$ 1,-\$ 5)$ ), are in a cluster by themselves.

18. $27.8 \%, \mathrm{p}<0.0001$.

19. Thus the beliefs that subjects have about the general population and their own choices tend to agree.

20. Possible motives include an efficiency concern (since sending increases the total earnings of the players), and a fairness concern. Another alternative is that the laboratory framing (at the workplace with co-workers, with whom repeated 
interactions might be expected) leads subjects to treat the experiment as if it were a repeated game in which there is cooperative equilibrium.

21. Economic and Statistics Group (2007) Truckload Line-haul Driver Turnover Quarterly Annualized Rates. Truck. Act. Rpt. Vol. 15, 1.

22. The driver must deliver a load to a point many miles away by a target time, taking into account loading times, distances, speed limits, weather, traffic conditions, and especially, the government regulations governing allowable hours of service for drivers.

23. See SM. Personality factors also affect these outcomes in a natural way. This job pays piece rates, so that effort affects earnings on average, but there is significant variation outside the control of the driver. High values of Control make drivers more likely to quite, while high values of Achievement make them less likely to get fired.

24. Clark G (2007) A Farewell to Alms: A Brief Economic History of the World (Princeton University Press, Princeton, NJ).

25. Of our three CS measures, the IQ index has the clearest claim to a genetic component, while the numeracy index most clearly has an acquired one. But nothing in our argument commits us to a particular view about the balance of nature and nurture in the origin of CS's.

26. Factor analysis of the three measures yields a single factor: see the SM for details.

27. Raven J, Raven JC, \& Court JH (2000) in Manual for Raven's Progressive Matrices and Vocabulary Scales (The Psychological Corporation, San Antonio, TX ).

28. In this and the prior measure, two subjects selected at random were paid for correct answers.

29. Subjects were paid for each round they won.

30. Luce R (2000) Utility of Gains and Losses (Lawrence Erlbaum Associates, Mahwah, NJ).

31. Two future payments (in nine and in thirty days) were offered by mail.

32. Kaplan EL \& Meier P (1958) Nonparametric estimation from incomplete observations. J. Amer. Statistical Assoc. 53, 457-481. 


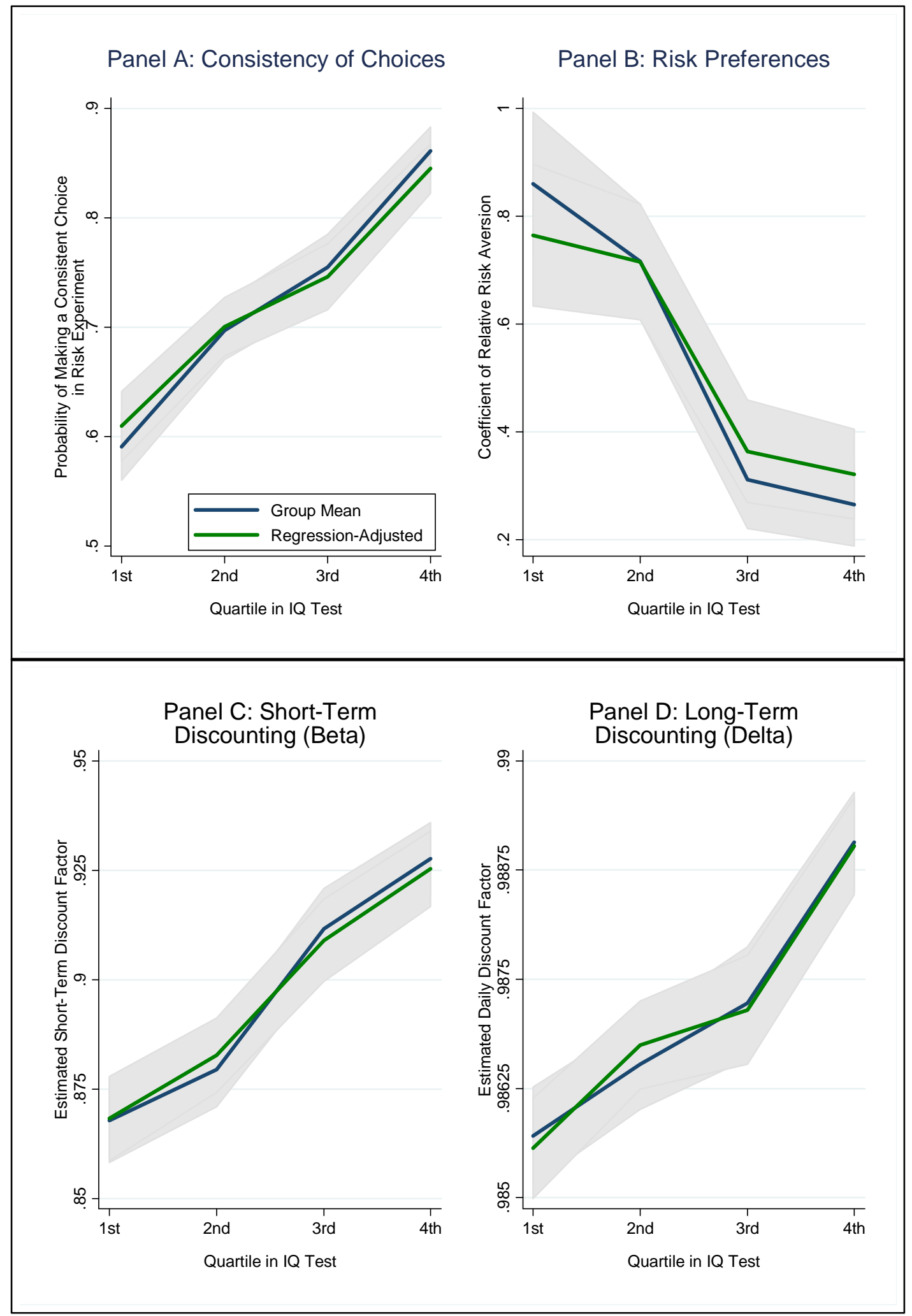

Figure 1 


\section{Figure 1: IQ and economic preferences}

Blue lines represent unconditional averages by quartile of IQ. Green lines are regression-adjusted averages, controlling for demographic and socio-economic variables. Standard errors are adjusted for clustering on individuals where more than one observation is used.

Panel A: IQ and Consistency of choices

Panel B: IQ and coefficient of relative risk aversion

The coefficient is estimated from choices over lotteries with positive outcomes, under the assumption that the subject has a power utility function on monetary payments (known as Constant Relative Risk Aversion utility function). The reported coefficient is 1 minus this power: this coefficient is a measure of his risk aversion.

Panel C: IQ and short-run time preferences. Panel D: IQ and long-run time preferences.

Short and long-run discount factors are estimated according to the beta-delta model. In this model, payments in the future are discounted in two ways. All future payments have a common discount beta compared to present (today) payments. This factor measures the loss for the individual of not receiving an immediate payment. All future payments are discounted by the factor delta to the power of the distance in the future of the payment: this factor measures the long run impatience. 


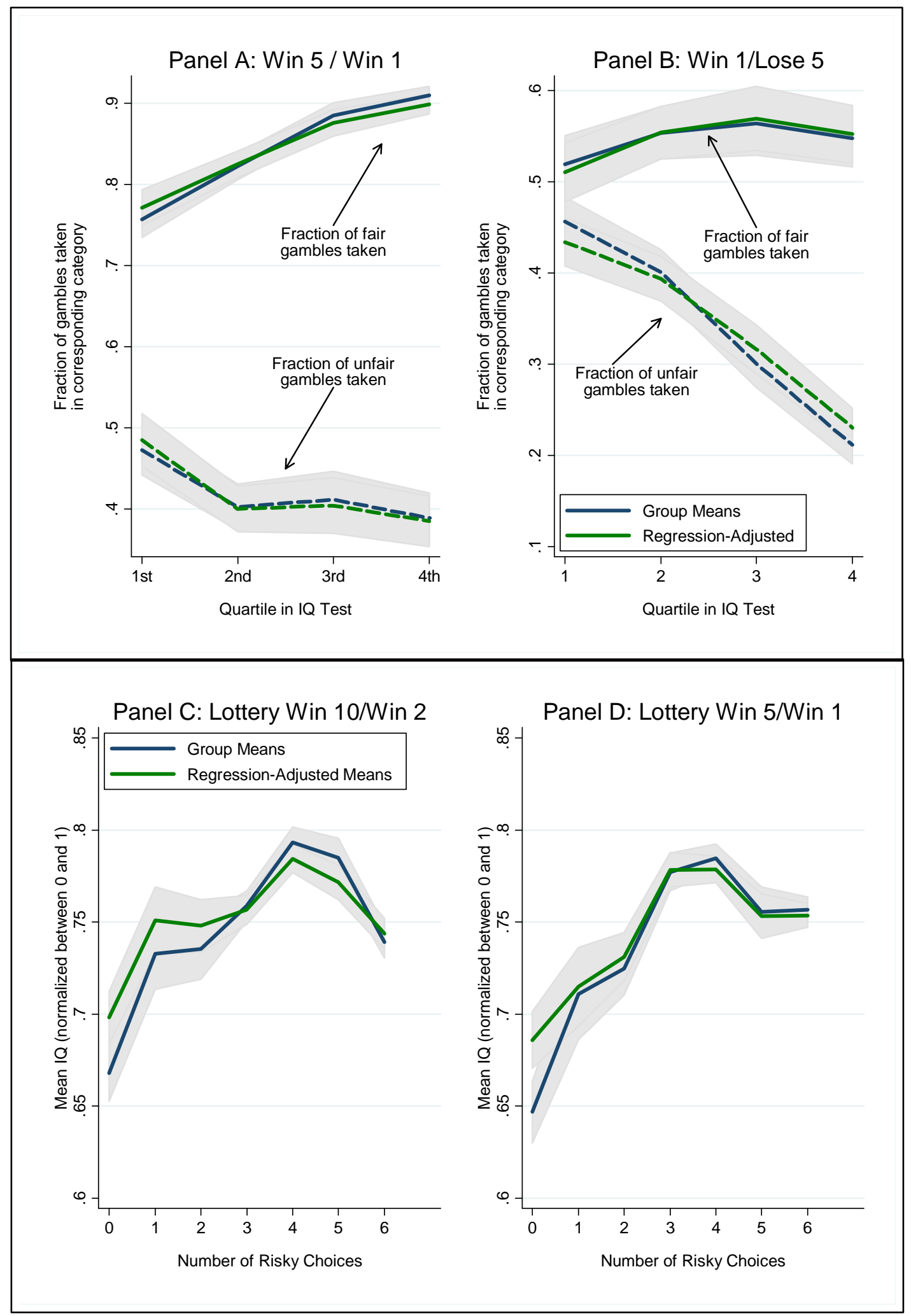

Figure 2 


\section{Figure 2:}

Panels A, B: Lower Cognitive Skills are associated with risk aversion in gains and risk seeking in losses

We say that a subject chooses a fair gamble if he chooses the lottery when the expected value of the lottery is larger than the certain amount. The certain amount is interpreted as the opportunity cost of the lottery, so the subject chooses a fair gamble if the expected net gain is positive. The figure reports the fraction of choice of fair and unfair gambles with the (win 5/win 1) lottery (gains) and the (win 1/ lose 5) lottery (losses). Blue lines and green lines are as in Figure 1.

\section{Panels C, D: Cognitive Skills peak near risk neutrality}

Each of the seven categories on the horizontal axis is given by the number of times the subject chooses the lottery instead of the certain amount. This is a measure of the willingness to take risks. The vertical axis reports the mean IQ for each category, normalized to lie between 0 and 1 . Blue lines and green lines are as in Figure 1. 


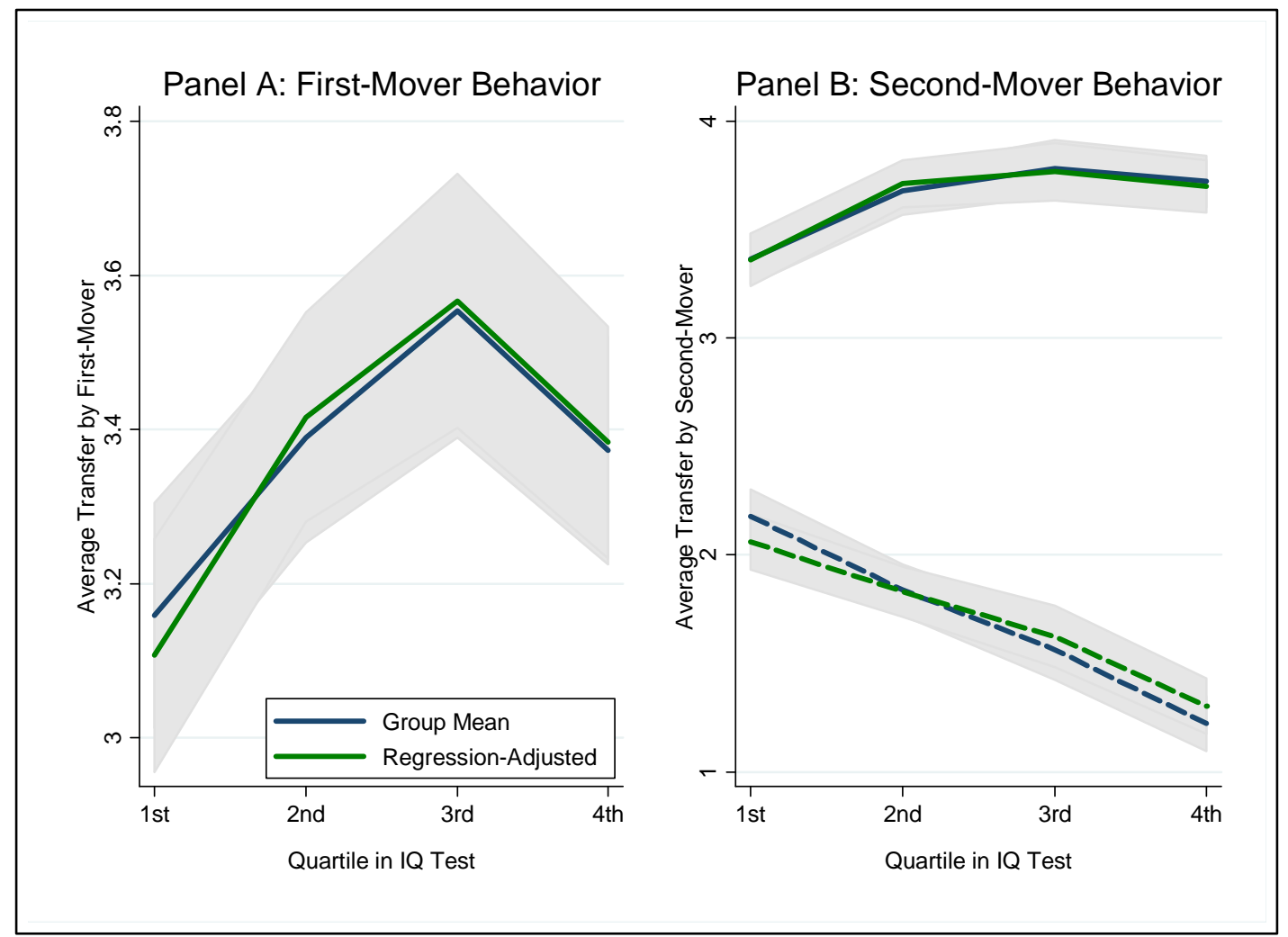

Figure 3: Behavior in the sequential prisoner's dilemma game

Blue lines and green lines are as in Figure 1.

\section{Panel A First mover behavior}

The figure reports the mean transfer, by quartiles of IQ. The mean transfer of the first mover for the entire sample was 3.353 (SE 0.071). The difference in transfers between the two groups is significant, even after we control for the different beliefs that subjects have of the reciprocal transfer choices of the second mover, and different utility functions.

\section{Panel B Second mover behavior}

The figure reports the mean transfer of second movers, conditional on the transfer of the first mover, by IQ quartile. The bottom curve describes the response to a $\$ 0$ transfer, and the top one the response to the $\$ 5$ transfer. 

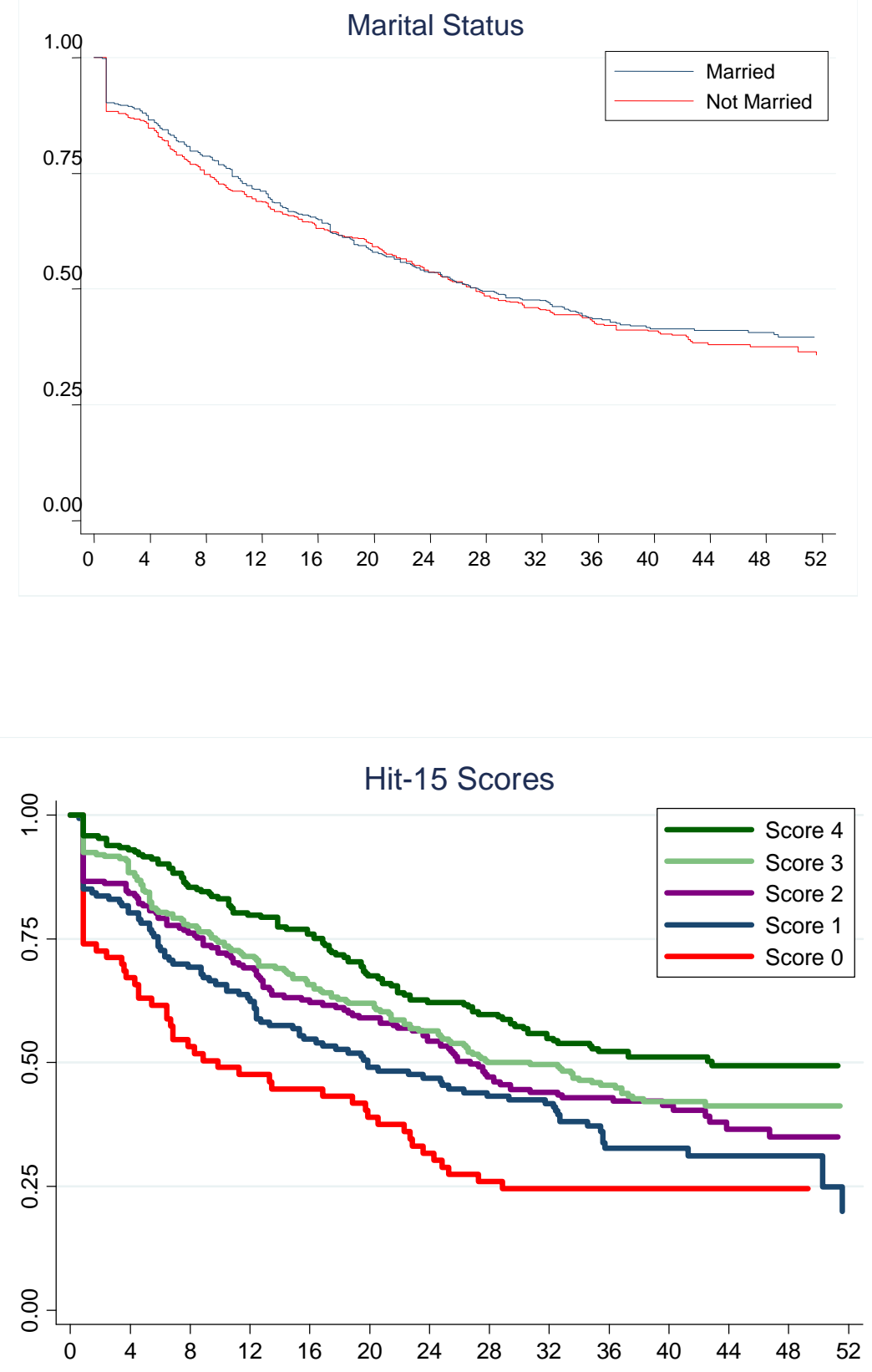

Figure 4, Panels A and B: IQ and survival in the firm

The panels report the empirical estimate of the survival function (Kaplan-Meyer) for all types of exits from the job. The time unit is weeks of job tenure. The vertical axis reports the survival rate. 


\title{
Cognitive skills explain economic preferences, strategic behavior and job attachment
}

\author{
Stephen Burks \\ Jeff Carpenter \\ Lorenz Götte \\ Aldo Rustichini
}

Supporting Information 


\section{Contents}

1 Methods 3

1.1 Experimental Design . . . . . . . . . . . . . . . . . 3

1.2 List of Variables . . . . . . . . . . . . . . . . . . . . . 7

2 Preferences and IQ 9

2.1 Consistency . . . . . . . . . . . . . . . . . . . . . . . . . 9 9

2.2 Choices under Uncertainty . . . . . . . . . . . . . . . . 10

2.3 Choices over Time . . . . . . . . . . . . . . . . . . . . . . . . . . . . . . . . . . 10

2.4 Strategic Behavior . . . . . . . . . . . . . . . . . . 12

3 Preferences and Cognitive Skills 14

3.1 Choices under Uncertainty . . . . . . . . . . . . . . . . . . . 19

3.2 Choices over Time . . . . . . . . . . . . . . . . . . 23

4 Correlation among Preferences $\quad 28$

4.1 Correlation among Preferences over Risk . . . . . . . . . . . . . . . 28

4.2 Correlation among Preferences over Time . . . . . . . . . . . . . 30

4.3 Correlation among Preferences in Different Domains . . . . . . . . . 31

5 Strategic Behavior and Cognitive Skills 32

5.1 Beliefs and Behavior in the Game . . . . . . . . . . . . . . . 33

5.2 Behavior as First Mover . . . . . . . . . . . . . . . . . . . . . 39

5.3 Behavior as Second Mover . . . . . . . . . . . . . . . . . 41

6 Analysis of Exits from the Company 43

6.1 Empirical Estimates of the Survival rate . . . . . . . . . . . . . . . 43

6.2 Early and Late Exits . . . . . . . . . . . . . . . . . . . . . . . 44 


\section{Methods}

The data items collected in-person by the investigators were gathered during 23 Saturdays between December 5, 2005 and August 8, 2006, from driver trainees in the middle of a two-week basic training course operated by the cooperating firm at a location in the U.S. Midwest. Subjects took part in two 2-hour sessions in groups of 18 to 30 . Credit scores were available due to the credit contract signed by trainees, and the firm provided these, along with weekly updates on the employment status of the members of the subject pool, through April, 2007. This data was collected for the "New Hire Panel Study", which is Research Component Two of the Truckers \& Turnover Project, and a more detailed account of the design and of the context for the project may be found in [3].

\subsection{Experimental Design}

The part of the design utilized here includes the following components: three economic experiments involving individual choices, an interactive game of strategy, a cognitive skills measure in the form of a game against the computer, two conventional cognitive skills measures, a personality profile, and a demographic profile. In addition to a flat show-up fee ( $\$ 10$ at the beginning of each two-hour session), all tasks except the personality profile and the demographic profile were compensated on the basis of choices made or answers provided. Average total earnings were $\$ 53$, with a low of $\$ 21$ and a high of $\$ 168$.

\section{Subjects}

1,069 trainee drivers took part, which was $91 \%$ of those offered the chance to participate. 3 of the subjects withdrew from the experiment, so the final sample consisted of 1,066 subjects. Because adjustments were made to two tasks shortly after data collection began, as noted below, the sample size is 892 when both these measures are utilized.

\section{Risk and Ambiguity Aversion}

In the risk aversion experiment there were 24 choices divided into four blocks of six choices each. There were two possible options for each choice: an amount of money received with certainty, versus a lottery paying a higher dollar amount or a smaller one, depending on whether a green or a blue chip was drawn from a bowl publicly observed to contain five poker chips of each color. Subjects also chose the color giving them the higher payoff, so the outcome was described as "a larger amount if your color is drawn and a smaller amount if the other color is drawn". There were four lotteries, with the following pairs of monetary outcomes: $(10,2)$, $(5,1),(5,-1)$, and $(1,-5)$. The one question on which all subjects were paid was drawn from a separate bowl with 24 numbered poker chips, prior to the draw of the winning color. 
The experiment on ambiguity aversion used the same choices as the risk aversion experiment, except that the subjects did not have full information on the probability of the two outcomes of the lottery options. Instead, two blue poker chips and two green poker chips were publicly placed in the bowl used to determine the winning color, and then out of sight of the subjects six more chips were added, which could be all green, all blue, or any mixture thereof. As a result, subjects only knew that there was at least a $20 \%$ chance that green would be drawn and at least a $20 \%$ chance that blue would to be drawn. The rest of the design was identical to the risk aversion task.

\section{Time Preferences}

In this experiment subjects had to make 28 choices, divided into four blocks of seven choices each. There were two possible options for each choice, a smaller amount of money paid earlier and a larger amount of money paid later. Each of the four blocks of seven choices had the same format. The amount for the higher payoff at a later date was in every case $\$ 80$ and the amount for the lower payoff at an earlier time varied between a maximum of $\$ 75$ and a minimum of $\$ 45$, with decrements of $\$ 5$. The experiment was always run on Saturday. The pair of dates were respectively today (Saturday) vs. tomorrow (Sunday), today vs. Thursday, Monday vs. a week from Monday, and Monday vs. 4 weeks from Monday. The question for payment was drawn first from a bowl with 28 numbered chips, and then the two subjects who were paid were selected by drawing from a separate bowl of numbered chips. Subjects departed the training school on the Friday following the data collection event, so the last two payments mentioned were made by mail when subjects chose them.

\section{Sequential Prisoner's Dilemma}

The extensive form of the game is the following: Person 1 (the first mover) and Person 2 (the second mover) each are allocated $\$ 5$. Person 1 can send either $\$ 0$ or $\$ 5$ to Person 2, and Person 2 can respond by sending $\$ 0, \$ 1, \$ 2, \$ 3, \$ 4$, or $\$ 5$ back. All funds sent are doubled by the researchers.

Each subject made both an unconditional decision for the first mover role, and a conditional one for the second mover role (first how to respond if the other sends $\$ 0$, and second how to respond if the other sends $\$ 5$, doubled to $\$ 10$.) Subjects were randomly matched and their role selected by the computer, after their decisions. This is a variant of the task used in [2].

Before each decision screen, subjects were also asked how they thought other participants in the room would act in this experiment. The first question was "What percent of the participants do you think will send their \$5 as Person 1?" and payed $\$ 1$ if the subject was correct within plus or minus $5 \%$. The second and third questions were "If Person 1 does not send/does send, what is the average amount that participants in this room will send back?" and payed $\$ 1$ each if the subject was within plus or minus $\$ 0.25$ of each of the two actual averages. 


\section{Hit 15 Task}

The Hit 15 task is a game between subject and computer. The computer and the subject take turns adding points to the "points basket" and in each turn the subject or the computer must add either one, two, or three points to the points basket. The goal is to be the first player to reach 15 points.

The game was played for five rounds, and the number of points in the points basket at the beginning of the round varied, and the computer and participant took turns going first. The first round was a practice round set to give the subjects an example of how the first stage of backward induction works. The subjects were paid $\$ 1$ for each round that they won after the first. 892 subjects have a score on this measure. This is the same game that is studied in [7].

\section{IQ Measurement}

The IQ instrument used is a licensed computerized adaptation of the Standard Progressive Matrices (SPM) by J.C. Raven [14]. It consists of five sections (A-E), each containing 12 questions. Each question is presented as a graphic image. On top a large rectangular box contains some kind of a pattern with a piece missing out of the lower right hand corner. On the bottom are six (or eight) possible pieces that could be used to complete the image on top. Each section starts with easy images, and becomes progressively more difficult, and the later sections are more difficult than the earlier ones.

Due to the time constraints the first section of the SPM was omitted. In addition, while we did not announce a time constraint at the beginning of the SPM, we halted activity at 31 minutes, with a prior warning at 28 minutes. Initial analysis showed that this affected the performance of a significant subset of subjects on section E, so the score used herein is the sum of correct answers on sections B, C, and D, scaled up by five thirds.

After both verbal and written instructions and two practice questions, subjects filled out a "confidence question" that asked how they thought they would do as compared to other subjects in the room, i.e. in which quintile their score would be (top 20\%, bottom 20\%, etc.) When the Raven's task had been completed, the same confidence question was asked again. Subjects were paid an additional $\$ 2$ for placing themselves in the correct quintile. In addition, two subjects were randomly chosen to be paid $\$ 1$ per correct answer, for a total possible earnings of $\$ 48$ each for their answers. 1,015 subjects have scores on this instrument

\section{Numeracy}

This instrument is part of the test of adult quantitative literacy from the Educational Testing Service. The full instrument consisted of two sections, of which only the first section was used. The section was made up of 12 questions and subjects were given exactly 20 minutes to complete the test. The test required subjects to be able to add, subtract, compare numbers, fill out a form, and to be able to read and understand a short problem, among other things. 
As with the non-verbal IQ, after instructions and a brief practice question, subjects filled out a "confidence question" that asked them how they thought

they would do as compared to other subjects in the room, by quintiles. When the numeracy task had been completed, the same confidence question was asked again. Subjects were paid an additional $\$ 2$ for placing themselves in the correct quintile. Two subjects were randomly chosen to be paid $\$ 2$ per correct answer, for a total possible earnings of $\$ 24$ each for their question answers.

\section{Personality Profile}

The Multidimensional Personality Questionnaire (MPQ) is a standard personality profile instrument [12]. It consists of 11 different scales that represent the following primary trait dimensions: wellbeing, social potency, achievement, social closeness, stress reaction, alienation, aggression, control, harm avoidance,traditionalism, and absorption. The short version used in the study has 154 multiple choice questions. An example of one question would be, "At times I have been envious of someone." Almost all of the 154 questions have the same four possible answers: "Always True", "Mostly True", "Mostly False", and "Always False".

\section{Demographic Profile}

The investigators asked participants to answer a series of questions designed to locate them within standard demographic categories (e.g. height, weight, age, gender, and marital status), and to provide basic socio-economic information, such as past experience in the labor market, and earnings information.

\section{Credit Scores}

The credit score is the FICO-98 (tm), purchased by the cooperating firm from the Fair Isaac Corporation. 942 of the trainees had a credit score, and the balance were reported to have insufficient identifiable data in their credit record to permit the computation of the FICO-98.

\section{Employment Status}

The firm provided weekly updates through April 7, 2007, on the employment status of the participants. This included a list of those who failed to complete the last week of training (until one week after we stopped inducting new participants), and also a list of those drivers who had completed training who had separated during the week being reported. In both cases the data indicated whether the separation was a voluntary quit or a discharge. See Table ?? for details.

\section{Statistical Analysis}

The analysis was conducted with Stata, Stata Corp, College Station, TX, Release 10/SE. 


\subsection{List of Variables}

\begin{tabular}{llc}
\hline \hline Name of the Variable & Description & Range \\
\hline \multirow{2}{*}{ Age } & Demographic & \\
Married & Age of the Subject & 21 to 69 \\
Male & Marital Status & $\{0,1\}$ \\
Height & Gender (=1 if male) & $\{0,1\}$ \\
Weight & Height in inches & 59 to 70 \\
& Weight in pounds & 110 to 351 \\
IQIndex & Cognitive Abilities & \\
Numeracy & Normalized Score in the Sections B, C, D of the SPM test & {$[0,1]$} \\
Hit15Index & Normalized Score in the Numerical Ability Test & {$[0,1]$} \\
& Normalized Score in the Hit15 test & {$[0,1]$} \\
PDSendP1 & Experimental Economic Choice & \\
PDSendP2 $2_{0}$ & Amount sent as first mover & $\{0,5\}$ \\
PDSendP2 25 & Amount sent as second mover, after $\$ 0$ transfer & $\{0,5\}$ \\
RAAcc & Amount sent as second mover, after $\$ 5$ transfer & $\{0,5\}$ \\
RAAcc & Choices of the Lottery in the Risky Choice & $\{0,24\}$ \\
TPFut & Choices of the Lottery in the Ambiguous Choice & $\{0,24\}$ \\
\hline \hline
\end{tabular}

Table 1: List of the main demographic and experimental variables. The range is the potential range of the variable. For instance, the IQIndex is a normalization to $[0,1]$ obtained by dividing the variable by the maximum possible value. The effective range of the variable is $[0.277,1]$. A variable name preceded by an $n$ indicates that the variable has been normalized to have an effective range between 0 and 1 , that is, if $X$ is the value of the variable, $n X=\frac{X-\min X}{\max X-\min X}$., 


\begin{tabular}{llr}
\hline \hline Name of the Variable & Description & Range \\
\hline & Socio-Economic Variables & \\
YrsOfSchool & Years of Schooling & 7 to 18 \\
OppIncome & Income in an alternative usual job & 5 to 75 \\
Income & Income from usual jobs & 5 to 75 \\
HouseholdIncome & Sum of Income and OppIncome & 10 to 150 \\
ExperienceR & Years of Experience on the Road & 0 to 5 \\
LongestDur & Longest Duration in years in a company & 0 to 40 \\
LengthRJ & Months in a regular job in the last two years & 0 to 24 \\
CreditRisk & Credit Score (FICO98) & 0 to 821 \\
\hline \hline
\end{tabular}

Table 2: List of Socio-Economic Variables.

Absorption
Achievement
Aggression
Alienation
Control
Harm Avoidance
Social Closeness
Social Potency
Stress Reaction
Traditionalism
Wellbeing
Invalidity

Table 3: List of MPQ and Psychological Variables. 


\section{Preferences and IQ}

In the section below we explain the procedures underlying the figures in the main text, which establish a link between preferences and cognitive skill. The procedure is based on two steps: first we estimate parameters describing the preferences, and then we establish the relation between these parameters and a measure of cognitive skill.

For the second step we run a regression in which the parameter value describing the subject's preference is the dependent variable, and the independent variables are the indicator or dummy variables $I_{j i}, j, j=1, \ldots, 4$, for the quartiles of the relevant cognitive skill; these take the value 1 for the quartile in which the subject $i$ falls, and 0 otherwise. The use of quartiles allows for potential non-linearities in the relationship while keeping the regression specification simple and robust.

In order to make use of the data we have on other factors that could potentially confound the relationhsips we are exploring, we estimate the coefficients $\gamma_{j}^{C S}$ associated with the indicators $I_{j i}$ in two ways: "raw" and "adjusted". The latter differs from the raw estimate in that we add to the indicators a set of control variables on the right hand side of the regression. The control variables are:

i. schooling, classifying subjects into the the following groups: middle school, some college, technical school, college, graduate

ii. age and age squared

iii. household income (defined in section 1.2)

iv. gender

v. race, classifying subjects into the the following groups: African American, American Indian, Asian, Latino, White

\subsection{Consistency}

We define as consistent an individual who displays at most one switching point in each block of choices. In other words, if an individual $i$ makes an inconsistent choice in any one of the four blocks, we label him as inconsistent, and set the corresponding variable consis $s_{i}=0$; else this variable is equal to 1 . We then estimate a linear probability model

$$
\text { consis }_{i}=I_{i} \gamma^{C S}+x_{i} b+e_{i}
$$

where $I_{i}$ is the vector of dummy variables for subject $i$ 's quartile of cognitive skill with $\gamma^{C S}$ the vector of corresponding coefficients, $x_{i}$ is the vector of control variables for subject $i$ with $b_{i}$ the vector of corresponding coefficients, and $e_{i}$ is an error term. To display the impact of cognitive skills on the frequency of consistent choices, in Figure 1, Panel A we plot the four estimated values of $\gamma_{j}^{C S}$, with their standard error bands, both with and without the control variables. 


\subsection{Choices under Uncertainty}

We use the two blocks of choices in the experiment on choice under uncertainty in which the lotteries have positive outcomes to obtain two measures of relative risk aversion for each individual. The subjects have to decide between a safe option and a 50/50 gamble in which they can win $\$ 10$ or $\$ 2$ in one choice block, and a $50 / 50$ gamble in which they can win $\$ 5$ or $\$ 1$ in the other. For each block, we calculate the coefficient of relative risk aversion needed to rationalize the choice the individual made, assuming a CRRA utility function.

Specifically, in block 1, a subject has to choose between each of a monotonically increasing sequence of sure payments $p_{j}$, and a 50/50 gamble in which he can either win $\$ 10$ or win $\$ 2$. Suppose individual $i$ takes the gamble at step $h$, but switches to the certain amount at step $h+1$. We assume that the individual would be indifferent between the gamble and the certain payment at the midpoint $0.5 p_{h}+0.5 p_{h+1}$ between the two certain payments $p_{h}$ and $p_{h+1}$. We further assume that the individual's utility function is given by

$$
u(c)=\frac{c^{1-\sigma}}{1-\sigma}
$$

where $c$ is consumption in dollars and $\sigma$ is the coefficient of relative risk aversion. We solve for the corresponding coefficient of relative risk aversion $\sigma_{i}$ :

$$
0.5 u(10)+0.5 u(2)=0.5 u\left(p_{h}\right)+0.5 u\left(p_{h+1}\right)
$$

We conduct the analogous procedure to calculate the coefficient of relative risk aversion in the case of the lottery in which an individual can win either $\$ 5$ or $\$ 1$. With these two calculated values of $\sigma$ for each individual at hand, we estimate the following regression of $\sigma$ on the quartiles of cognitive skill and control variables:

$$
\sigma_{i, k}=\alpha_{k} I_{k}+\gamma_{i}^{C S} I_{i}+x_{i} b+e_{i, k}
$$

where $\sigma_{i, k}$ was calculated as specified above for individual $i$ in choice $k, I_{k}$ is a vector of dummy variables, one for each of the two choice blocks described above (win $10 /$ win 2 or win 5/win1), with the corresponding vector of "fixed effect" coefficients

$\alpha_{k}, I_{i}$ is the vector of four dummy variables for the quartiles of cognitive skill, with $\gamma^{C S}$ the vector corresponding coefficients, and $e_{i, k}$ is an appropriate error term. The $\gamma_{j}^{C S}$ 's, together with their estimated standard errors, are plotted in Figure 1, Panel B, both with and without the usual set of control variables. Because we use two different $\sigma_{i, k}$ values that were calculated for the same individual, we adjust the standard errors for clustering on individuals.

\subsection{Choices over Time}

To allow for a possible difference between short-term and long-term discounting, we adopt the model of $(\beta, \delta)$-preferences proposed in [13] and in [10]. If an individual has $(\beta, \delta)$-preferences then the amount $x$ such that he is indifferent between 
receiving $x$ earlier or receiving $\$ 80$ after $t$ days is given by

$$
u(x)=\beta \delta^{t} u(80)
$$

if the earlier payment occurs today, and

$$
u(x)=\delta^{t} u(80)
$$

otherwise. Taking logs, we get

$$
\log u(x)-\log u(80)=I \log \beta+t \log \delta
$$

where $I=1$ if the earlier payment occurs today, and 0 otherwise.

In order to estimate $\beta$ and $\delta$, we assume that $u$ is approximately linear over the relevant range. Then we can write the relationship between $x_{i}$ and individual $i$ 's discount factors $\beta_{i}$ and $\delta_{i}$ in choice $k$ as:

$$
\log x_{i, k}-\log 80=I_{k} \log \beta_{i}+t_{k} \log \delta_{i}+e_{i, k}
$$

where $e_{i, k}$ is an appropriate error term. We let both discount factors depend on cognitive abilities, and estimate a separate discount factor for each quartile of cognitive abilities. In particular, for the short-term discount factor $\beta$, we specify

$$
\log \beta_{i}=I_{i}^{b} b_{j}^{C S}+x_{i} b
$$

where $I^{b}$ is the vector of four dummy variables for the four quartiles of cognitive skill, with $b_{j}^{C S}$ the corresponding coefficients. Similarly, for the long-term discount factor $\delta$, we specify

$$
\log \delta_{i}=I_{i}^{d} d_{j}^{C S}+x_{i} b
$$

We substitute equations 2.9 and 2.10 into 2.8, and estimate the resulting equation using OLS. Because each individual makes 4 choices, we adjust the standard errors for clustering on individuals, as the distinct residuals for an individual cannot be viewed as independent. The resulting estimates of the (short term) $b_{j}^{C S}$ 's are presented in Figure 1, Panel C, while the (long term) $d_{j}^{C S}$ 's are in Panel D, both with and without the control variables.

\section{Gains and Losses}

We define two measures for risk preferences: the fraction of fair gambles accepted, and the fraction of unfair gambles accepted. We define a fair (unfair) gamble as a choice in which the uncertain payoff has a higher (lower) expected value than the sure option. We say that a subject accepts a fair (unfair) gamble if he chooses the lottery as opposed to the certain payment in the relevant case. For example, in the risk experiment choice block involving the lottery (win $\$ 5 /$ win $\$ 1$ ), there are four fair gambles, and one unfair gamble. If an individual accepted 3 of the fair gambles, the fraction of fair gambles accepted is 0.75 .

We then run the following regression: 


$$
\text { fair }_{i}=I_{i} \gamma_{j}^{C S}+x_{i} b+e_{i}
$$

where the quartile dummy variables and related coefficients, and the control variables and related coefficients, are both defined as in previous sections. The two lotteries of interest are the (win $\$ 5 /$ lose $\$ 1$ ) and (win $\$ 1 /$ lose $\$ 5$ ) ones. We repeat these estimations with the fraction of unfair gambles taken as the dependent variable for the two lotteries. Figure 2, Panels A and B display the resulting coefficient estimates for the $\gamma_{j}^{C S}$ 's, with estimated standard errors, again with and without control variables.

\section{Cognitive Skills and Risk Attitudes}

Our data suggest that the relation between cognitive skills and risk preferences is non-monotonic. To see this, we plot the predicted CS level as a function of the number of risky choices a subject made in a particular lottery experiment. Specifically, we estimate the following regression of the index of $C S$ used here, the IQ score, on a vector of dummy variables capturing the number of the times the subject chooses the lottery:

$$
\left.C S_{i}=\gamma_{k i} I_{i} \text { (made } k \text { risky choices }\right)+x_{i} b+e_{i}
$$

Since an individual can make between zero and six risky choices, there are seven elements in the vectors $\gamma_{k i} I_{i}$ of dummy variables and associated coefficients. As in the estimates described in the subsections above, we run a specification of 2.12 both with and without the usual set of control variables $x_{i}$. Furthermore, we estimate 2.12 separately for the choices involving the (win $\$ 10 /$ win $\$ 2$ ) and (win $\$ 5 /$ win $\$ 1$ ) lotteries. The results are displayed, with estimated standard errors, in Figure 2, Panels C and D.

\subsection{Strategic Behavior}

\section{Method for the First-Mover}

The dependent variable is the amount sent by the first mover. The amount is either $\$ 0$ or $\$ 5$. Thus, we estimate the regression

$$
\operatorname{sent}_{i}=I_{i} \gamma_{j}^{C S}+x_{i} b+e_{i}
$$

where sent $_{i}$ is the amount sent by the first-mover, and $I_{i}$ is the standard vector of four dummy variables for the four quartiles of CS, together with associated

coefficients $\gamma_{j}^{C S}$, and the control variables are defined as usual. As in previous estimates, we run a specification of 2.13 with and without the control variables $x_{i}$.

\section{Method for the Second-Mover}

The dependent variable is the amount returned by the second mover. Since the second-mover can condition his choice on the first-mover's amount sent, we have 
to estimate two regressions. We estimate the equation

$$
\operatorname{return}_{5}^{i}=I_{i} \gamma_{j(i)}^{C S}+x_{i} b+e_{i}
$$

where return $_{5}^{i}$ is the amount returned by the second mover if the first mover sent $\$ 5$, and the other variables are defined as in the previous equation. As usual, we run a specification of 2.14 with the control variables $x_{i}$. We also estimate the analogue to 2.14 for the case in which the first mover did not send any money. Figure 3, Panels A and B, displays the results coefficient estimates $\gamma_{j}^{C S}$ with estimated standard error bands. 


\section{Preferences and Cognitive Skills}

\section{Summary Statistics on Cognitive Skills}

\section{Raven Score Density for Drivers and SPM sample}

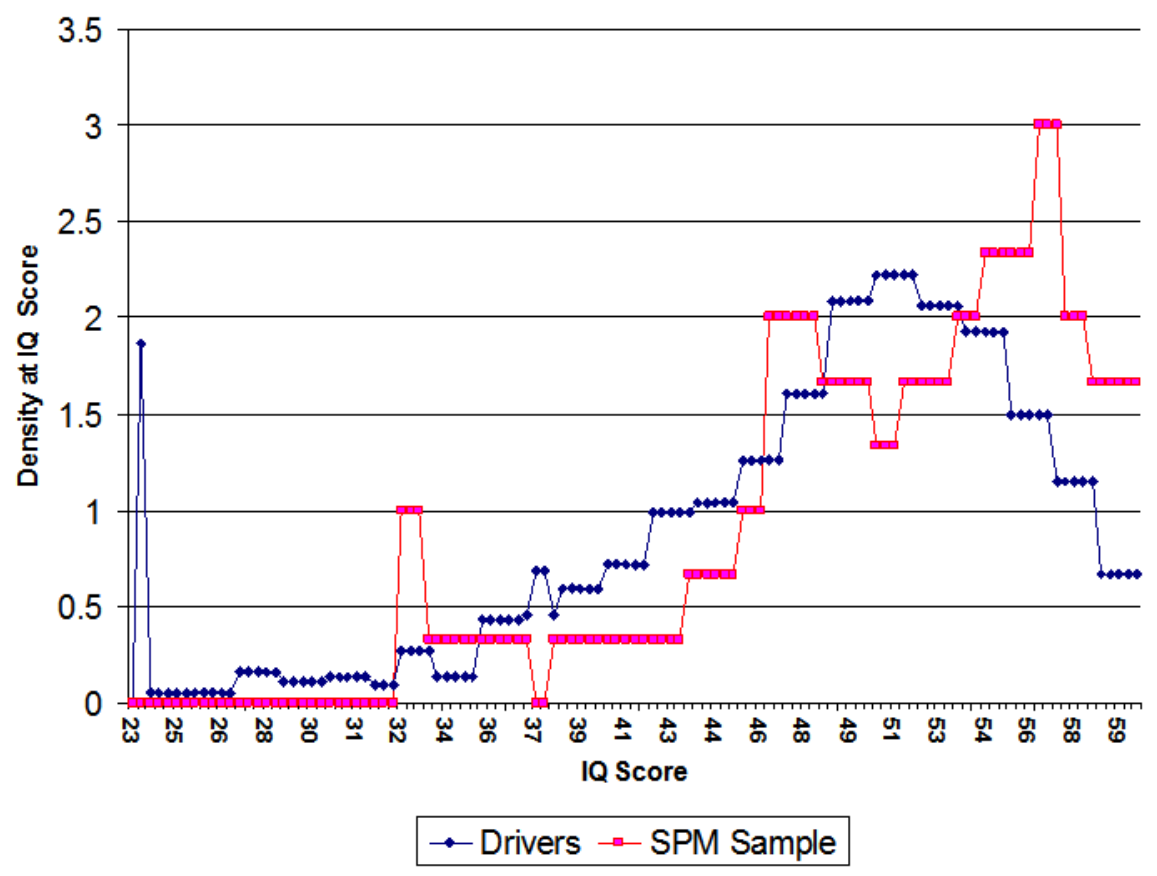

Figure 1: Distribution of the score for the IQ test (Raven's matrices) in the sample of subjects and in the general population, according to the SPM sampling. 


\section{Factors affecting Cognitive Skills}

\begin{tabular}{lccc}
\hline \hline & $\begin{array}{c}\text { IQIndex } \\
\mathrm{b} / \mathrm{se}\end{array}$ & $\begin{array}{c}\text { Numeracy } \\
\mathrm{b} / \mathrm{se}\end{array}$ & $\begin{array}{c}\text { Hit15Index } \\
\mathrm{b} / \mathrm{se}\end{array}$ \\
\hline White & $0.0428^{* * *}$ & $0.130^{* * *}$ & $0.183^{* * *}$ \\
& $(0.013)$ & $(0.019)$ & $(0.027)$ \\
Male & $-0.0299^{* *}$ & $-0.024^{*}$ & 0.083 \\
& $(0.015)$ & $(0.023)$ & $(0.032)$ \\
nAge & $-0.128^{* * *}$ & 0.021 & $-0.289^{* * *}$ \\
& $(0.021)$ & $(0.032)$ & $(0.045)$ \\
nSHeight & 0.0111 & 0.062 & $0.117^{*}$ \\
& $(0.0273)$ & $(0.068)$ & $(0.057)$ \\
constant & $0.829^{* * *}$ & $0.581^{* * *}$ & $0.416^{* * *}$ \\
& $(0.023)$ & $(0.035)$ & $(0.049)$ \\
\hline & & & \\
$R^{2}$ & 0.048 & 0.052 & 0.104 \\
$\mathrm{~N}$ & 839 & 841 & 835 \\
\hline \hline
\end{tabular}

Table 4: Factors affecting IQ, Numeracy and Hit 15 Score. The $n$ Age variable is the variable Age normalized to be between 0 and 1. The variable $n S H e i g h t$ is obtained in two steps. First we subtract the mean of the variable Height for subjects of the same gender from the variable of the subject. Then the variable is normalized to be between 0 and 1 , to obtain $n$ SHeight . 


\section{Factor Analysis of Cognitive Abilities}

The next tables show that the three measures of cognitive skills we use are significantly and strongly correlated. Factor analysis shows a single factor for the three variables.

\begin{tabular}{lcccc}
\hline \hline Variable & Factor 1 & Uniqueness & Proportion & Cumulative \\
\hline Factor1 & 1.1828 & 1.3126 & 1.3906 & 1.3906 \\
Factor2 & -0.1298 & 0.0725 & -0.1527 & 1.2380 \\
Factor3 & -0.2024 &. & -0.2380 & 1.0000 \\
\hline \hline
\end{tabular}

Table 5: Factor analysis and correlation. Number of observations $=886$. LR test: independent vs. saturated: $\chi^{2}(3)=496.62$, Prob $>\chi^{2}(3)=0.00001$. Only one factor has eigenvalue larger than 1.

\begin{tabular}{ccc}
\hline \hline Variable & Factor 1 & Uniqueness \\
\hline Numeracy & 0.6678 & 0.5541 \\
IQIndex & 0.6387 & 0.5921 \\
Hit15Index & 0.5736 & 0.6710 \\
\hline \hline
\end{tabular}

Table 6: Factor loadings (pattern matrix) and unique variances. 


\section{Consistency of Choices}

\section{Consistency of Choices in Time, Risk and Ambiguity}

\begin{tabular}{lccc}
\hline \hline & $\begin{array}{c}\text { Cons. Time } \\
\text { me/(se) }\end{array}$ & $\begin{array}{c}\text { Cons. Risk } \\
\text { me/(se) }\end{array}$ & $\begin{array}{c}\text { Cons. Amb. } \\
\text { me/(se) }\end{array}$ \\
\hline IQ Index & $0.1226^{* *}$ & $0.3048^{* * *}$ & $0.1991^{* *}$ \\
& $(0.0616)$ & $(0.1041)$ & $(0.0737)$ \\
Hit15 Index & 0.0231 & 0.0529 & 0.0256 \\
& $(0.031)$ & $(0.0466)$ & $(0.0353)$ \\
Numeracy & $0.184^{* * *}$ & $.2379^{* * *}$ & $0.1367^{* * *}$ \\
& $(0.0444)$ & $(0.0702)$ & $(0.0525)$ \\
RAAcc & & $-0.0431^{* * *}$ & \\
& & $(0.0106)$ & \\
RAAccSq & & $0.002^{* * *}$ & \\
AAAcc & & $(0.0003)$ & $-.0252^{* * *}$ \\
AAAccSq & & & $0.0077)$ \\
& & & $0.0011^{* * *}$ \\
Prob $>\chi^{2}$ & 0.00001 & 0.00001 & 0.00001 \\
N & 884 & 884 & 884 \\
\hline
\end{tabular}

Table 7: Logit regression of the consistency of choice. The variable Cons. Time is equal to 1 if the subject is consistent in all the time choices, Cons. Risk is the correspondent variable for risky choices, and Cons. Amb. is the variable for ambiguous choices. The independent variables, IQIndex, Numeracy and Hit15 Index are all normalized to take values in the unit interval. The table reports the marginal effects. 


\section{Consistency of Risk Aversion with High and Low Stakes}

\begin{tabular}{lccc}
\hline \hline & $\begin{array}{c}\text { distance } \\
\mathrm{b} / \mathrm{se}\end{array}$ & $\begin{array}{c}\text { distance } \\
\mathrm{b} / \mathrm{se}\end{array}$ & $\begin{array}{c}\text { distance } \\
\mathrm{b} / \mathrm{se}\end{array}$ \\
\hline IQIndex & $-1.094^{* * *}$ & $-0.634^{*}$ & $-0.768^{* *}$ \\
& $(0.278)$ & $(0.345)$ & $(0.333)$ \\
Hit15Index & & -0.007 & -0.066 \\
& & $(0.151)$ & $(0.145)$ \\
Numeracy & & $-0.494^{* *}$ & $-0.542^{* *}$ \\
& & $(0.235)$ & $(0.225)$ \\
RAAcc & & & $0.064^{* *}$ \\
& & & $(0.030)$ \\
RAAccSq & & & $-0.004^{* * *}$ \\
& & & $(0.001)$ \\
_cons & $1.773^{* * *}$ & $1.740^{* * *}$ & $2.056^{* * *}$ \\
& $(0.227)$ & $(0.239)$ & $(0.284)$ \\
\hline & & & \\
$R^{2}$ & 0.015 & 0.019 & 0.106 \\
$\mathrm{~N}$ & 1013 & 884 & 884 \\
\hline \hline
\end{tabular}

Table 8: Regression of the distance between the coeafficient of risk aversion with lower and higher stakes. The variable distance is the square of the difference between the two coefficients. 


\subsection{Choices under Uncertainty}

\begin{tabular}{|c|c|c|c|}
\hline & $\begin{array}{r}\text { Risk Acc. } \\
\text { b/se }\end{array}$ & $\begin{array}{r}\text { Risk Acc. } \\
\text { b/se }\end{array}$ & $\begin{array}{r}\text { Risk Acc. } \\
\text { b/se }\end{array}$ \\
\hline \multirow[t]{2}{*}{ IQIndex } & $0.974^{* * *}$ & $0.945^{* *}$ & $1.017^{* *}$ \\
\hline & $(0.363)$ & $(0.377)$ & $(0.468)$ \\
\hline \multirow[t]{2}{*}{ HarmAvoidance } & -0.015 & -0.014 & -0.006 \\
\hline & $(0.010)$ & $(0.010)$ & $(0.011)$ \\
\hline \multirow[t]{2}{*}{ YrsOfSchool } & & -0.011 & -0.017 \\
\hline & & $(0.037)$ & $(0.039)$ \\
\hline \multirow[t]{2}{*}{ OppIncome } & & 0.004 & 0.006 \\
\hline & & $(0.004)$ & $(0.004)$ \\
\hline \multirow[t]{2}{*}{ ExperienceR } & & 0.041 & 0.037 \\
\hline & & $(0.032)$ & $(0.034)$ \\
\hline \multirow[t]{2}{*}{ LengthRJ } & & 0.002 & -0.000 \\
\hline & & $(0.006)$ & $(0.007)$ \\
\hline \multirow[t]{2}{*}{ CreditRisk } & & -0.000 & -0.000 \\
\hline & & $(0.000)$ & $(0.000)$ \\
\hline \multirow[t]{2}{*}{ Numeracy } & & & 0.035 \\
\hline & & & $(0.339)$ \\
\hline \multirow[t]{2}{*}{ Hit15Index } & & & 0.173 \\
\hline & & & $(0.208)$ \\
\hline \multirow[t]{2}{*}{ constant } & $3.594^{* * *}$ & $3.488^{* * *}$ & $3.059^{* * *}$ \\
\hline & $(0.477)$ & $(0.652)$ & $(0.701)$ \\
\hline$R^{2}$ & 0.010 & 0.013 & 0.016 \\
\hline $\mathrm{N}$ & 1016 & 1014 & 884 \\
\hline
\end{tabular}

Table 9: Variables affecting choices under risk, with lottery $(\$ 10, \$ 2)$. The dependent variable RiskAcc. is the number of choices of the lottery over the certain amount. See the section 1.2 for a definition of the independent variables. 


\begin{tabular}{|c|c|c|c|}
\hline & $\begin{array}{r}\text { Risk Acc. } \\
\text { b/se }\end{array}$ & $\begin{array}{r}\text { Risk Acc. } \\
\text { b/se }\end{array}$ & $\begin{array}{r}\text { Risk Acc. } \\
\text { b/se }\end{array}$ \\
\hline IQIndex & $\begin{array}{l}1.880^{* * *} \\
(0.585)\end{array}$ & $\begin{array}{c}1.423^{* *} \\
(0.600)\end{array}$ & $\begin{array}{r}0.361 \\
(0.738)\end{array}$ \\
\hline HarmAvoidance & $\begin{array}{l}-0.034^{* *} \\
(0.017)\end{array}$ & $\begin{array}{l}-0.031^{*} \\
(0.016)\end{array}$ & $\begin{array}{r}-0.019 \\
(0.018)\end{array}$ \\
\hline YrsOfSchool & & $\begin{array}{c}0.163^{\text {**** }} \\
(0.059)\end{array}$ & $\begin{array}{c}0.137^{* *} \\
(0.062)\end{array}$ \\
\hline OppIncome & & $\begin{array}{r}0.009 \\
(0.006)\end{array}$ & $\begin{array}{c}0.011^{*} \\
(0.006)\end{array}$ \\
\hline ExperienceR & & $\begin{array}{r}0.051 \\
(0.051)\end{array}$ & $\begin{array}{r}0.038 \\
(0.054)\end{array}$ \\
\hline LengthRJ & & $\begin{array}{r}-0.006 \\
(0.010)\end{array}$ & $\begin{array}{r}-0.011 \\
(0.011)\end{array}$ \\
\hline CreditRisk & & $\begin{array}{l}0.001^{* * *} \\
(0.000)\end{array}$ & $\begin{array}{c}0.001^{* *} \\
(0.000)\end{array}$ \\
\hline Numeracy & & & $\begin{array}{l}1.721^{* * *} \\
(0.535)\end{array}$ \\
\hline Hit15Index & & & $\begin{array}{r}0.247 \\
(0.328)\end{array}$ \\
\hline constant & $\begin{array}{l}2.511^{* * *} \\
(0.768)\end{array}$ & $\begin{array}{r}-0.361 \\
(1.036) \\
\end{array}$ & $\begin{array}{r}-0.698 \\
(1.106) \\
\end{array}$ \\
\hline$R^{2}$ & 0.016 & 0.044 & 0.061 \\
\hline $\mathrm{N}$ & 1016 & 1014 & 884 \\
\hline
\end{tabular}

Table 10: Variables affecting choices under risk, with lottery $(\$ 5, \$ 1)$. The dependent variable RiskAcc. is the number of choices of the lottery over the certain amount. See the section 1.2 for a definition of the independent variables. 


\begin{tabular}{|c|c|c|c|}
\hline & $\begin{array}{r}\text { Risk Acc. } \\
\text { b/se }\end{array}$ & $\begin{array}{r}\text { Risk Acc. } \\
\text { b/se }\end{array}$ & $\begin{array}{r}\text { Risk Acc. } \\
\text { b/se }\end{array}$ \\
\hline \multirow[t]{2}{*}{ IQIndex } & 0.177 & 0.360 & 0.744 \\
\hline & $(0.406)$ & $(0.421)$ & $(0.521)$ \\
\hline \multirow[t]{2}{*}{ HarmAvoidance } & -0.009 & -0.011 & -0.008 \\
\hline & $(0.012)$ & $(0.012)$ & $(0.013)$ \\
\hline \multirow[t]{2}{*}{ YrsOfSchool } & & -0.060 & -0.052 \\
\hline & & $(0.041)$ & $(0.044)$ \\
\hline \multirow[t]{2}{*}{ OppIncome } & & 0.002 & 0.004 \\
\hline & & (0.004) & (0.004) \\
\hline \multirow[t]{2}{*}{ ExperienceR } & & 0.047 & 0.056 \\
\hline & & $(0.036)$ & $(0.038)$ \\
\hline \multirow[t]{2}{*}{ LengthRJ } & & -0.005 & -0.003 \\
\hline & & (0.007) & (0.008) \\
\hline \multirow[t]{2}{*}{ CreditRisk } & & 0.001* & 0.000 \\
\hline & & $(0.000)$ & (0.000) \\
\hline \multirow[t]{2}{*}{ Numeracy } & & & -0.035 \\
\hline & & & (0.378) \\
\hline \multirow[t]{2}{*}{ Hit15Index } & & & -0.163 \\
\hline & & & $(0.232)$ \\
\hline \multirow[t]{2}{*}{ constant } & $4.638^{* * *}$ & $4.949 * * *$ & 4.511*** \\
\hline & $(0.533)$ & $(0.728)$ & $(0.781)$ \\
\hline$R^{2}$ & 0.001 & 0.008 & 0.009 \\
\hline $\mathrm{N}$ & 1016 & 1014 & 884 \\
\hline
\end{tabular}

Table 11: Variables affecting choices under risk, with lottery $(\$ 5,-\$ 1)$. The dependent variable RiskAcc. is the number of choices of the lottery over the certain amount. See the section 1.2 for a definition of the independent variables. 


\begin{tabular}{|c|c|c|c|}
\hline & $\begin{array}{r}\text { Risk Acc. } \\
\mathrm{b} / \mathrm{se}\end{array}$ & $\begin{array}{r}\text { Risk Acc. } \\
\mathrm{b} / \mathrm{se}\end{array}$ & $\begin{array}{r}\text { Risk Acc. } \\
\mathrm{b} / \mathrm{se}\end{array}$ \\
\hline IQIndex & $\begin{array}{l}-2.623^{* * *} \\
(0.485)\end{array}$ & $\begin{array}{l}-2.487^{* * *} \\
(0.505)\end{array}$ & $\begin{array}{l}-1.175^{*} \\
(0.620)\end{array}$ \\
\hline HarmAvoidance & $\begin{array}{l}-0.000 \\
(0.014)\end{array}$ & $\begin{array}{l}-0.002 \\
(0.014)\end{array}$ & $\begin{array}{l}-0.012 \\
(0.015)\end{array}$ \\
\hline YrsOfSchool & & $\begin{array}{r}-0.029 \\
(0.049)\end{array}$ & $\begin{array}{l}-0.016 \\
(0.052)\end{array}$ \\
\hline OppIncome & & $\begin{array}{l}-0.005 \\
(0.005)\end{array}$ & $\begin{array}{l}-0.001 \\
(0.005)\end{array}$ \\
\hline ExperienceR & & $\begin{array}{r}0.022 \\
(0.043)\end{array}$ & $\begin{array}{r}0.017 \\
(0.046)\end{array}$ \\
\hline LengthRJ & & $\begin{array}{l}-0.005 \\
(0.009)\end{array}$ & $\begin{array}{r}0.004 \\
(0.009)\end{array}$ \\
\hline CreditRisk & & $\begin{array}{r}0.000 \\
(0.000)\end{array}$ & $\begin{array}{r}0.000 \\
(0.000)\end{array}$ \\
\hline Numeracy & & & $\begin{array}{l}-1.072^{* *} \\
(0.450)\end{array}$ \\
\hline Hit15Index & & & $\begin{array}{l}-0.693^{* *} \\
(0.276)\end{array}$ \\
\hline constant & $\begin{array}{l}4.585^{* * *} \\
(0.637)\end{array}$ & $\begin{array}{l}4.940^{* * *} \\
(0.871)\end{array}$ & $\begin{array}{l}4.981^{* * *} \\
(0.929)\end{array}$ \\
\hline$R^{2}$ & 0.028 & 0.029 & 0.045 \\
\hline $\mathrm{N}$ & 1016 & 1014 & 884 \\
\hline
\end{tabular}

Table 12: Variables affecting choices under risk, with lottery $(\$ 1,-\$ 5)$. The dependent variable RiskAcc. is the number of choices of the lottery over the certain amount. See the section 1.2 for a definition of the independent variables. 


\subsection{Choices over Time}

\begin{tabular}{|c|c|c|c|}
\hline & $\begin{aligned} & \text { Future Pay. } \text { Acc. } \\
& \text { b/se }\end{aligned}$ & $\begin{aligned} & \text { Future Pay. } \text { Acc. } \\
& \text { b/se }\end{aligned}$ & $\begin{array}{r}\text { Future Pay. Acc. } \\
\text { b/se }\end{array}$ \\
\hline \multirow[t]{2}{*}{ IQIndex } & $1.873^{* * *}$ & $1.505^{* * *}$ & 0.420 \\
\hline & $(0.478)$ & $(0.490)$ & $(0.581)$ \\
\hline \multirow[t]{2}{*}{ HarmAvoidance } & -0.008 & -0.006 & 0.006 \\
\hline & $(0.014)$ & $(0.013)$ & $(0.014)$ \\
\hline \multirow[t]{2}{*}{ YrsOfSchool } & & $0.141^{* * *}$ & $0.105^{* *}$ \\
\hline & & $(0.048)$ & $(0.049)$ \\
\hline \multirow[t]{2}{*}{ OppIncome } & & 0.004 & 0.003 \\
\hline & & $(0.005)$ & $(0.005)$ \\
\hline \multirow[t]{2}{*}{ ExperienceR } & & 0.054 & 0.059 \\
\hline & & $(0.041)$ & $(0.043)$ \\
\hline \multirow[t]{2}{*}{ LengthRJ } & & 0.001 & -0.010 \\
\hline & & $(0.008)$ & $(0.009)$ \\
\hline \multirow[t]{2}{*}{ CreditRisk } & & $0.001^{* * *}$ & $0.001^{* * *}$ \\
\hline & & $(0.000)$ & $(0.000)$ \\
\hline Numeracy & & & $\begin{array}{l}1.847^{* * *} \\
(0.421)\end{array}$ \\
\hline Hit15Index & & & $\begin{array}{l}-0.067 \\
(0.258)\end{array}$ \\
\hline constant & $\begin{array}{l}4.199^{* * *} \\
(0.627)\end{array}$ & $\begin{array}{l}1.676^{* *} \\
(0.846)\end{array}$ & $\begin{array}{l}1.744^{* *} \\
(0.870)\end{array}$ \\
\hline$R^{2}$ & 0.016 & 0.047 & 0.071 \\
\hline $\mathrm{N}$ & 1016 & 1014 & 884 \\
\hline
\end{tabular}

Table 13: Variables affecting choices over time, today vs. tomorrow. The dependent variable FuturePay.Acc. is the number of choices of the future payment over the earlier one. See the section 1.2 for a definition of the independent variables. 


\begin{tabular}{|c|c|c|c|}
\hline & $\begin{array}{r}\text { Future Pay. Acc. } \\
\text { b/se }\end{array}$ & $\begin{array}{r}\text { Future Pay. Acc. } \\
\text { b/se }\end{array}$ & $\begin{array}{r}\text { Future Pay. Acc. } \\
\text { b/se }\end{array}$ \\
\hline \multirow[t]{2}{*}{ IQIndex } & $2.387^{* * *}$ & $2.025^{* * *}$ & 0.587 \\
\hline & $(0.541)$ & $(0.554)$ & $(0.669)$ \\
\hline \multirow[t]{2}{*}{ HarmAvoidance } & -0.022 & -0.023 & -0.013 \\
\hline & $(0.015)$ & $(0.015)$ & $(0.016)$ \\
\hline \multirow[t]{2}{*}{ YrsOfSchool } & & $0.128^{* *}$ & 0.079 \\
\hline & & $(0.054)$ & $(0.056)$ \\
\hline \multirow[t]{2}{*}{ OppIncome } & & 0.003 & 0.002 \\
\hline & & $(0.005)$ & (0.006) \\
\hline \multirow[t]{2}{*}{ ExperienceR } & & 0.020 & 0.038 \\
\hline & & $(0.047)$ & $(0.049)$ \\
\hline \multirow[t]{2}{*}{ LengthRJ } & & -0.001 & -0.012 \\
\hline & & (0.009) & (0.010) \\
\hline \multirow[t]{2}{*}{ CreditRisk } & & $0.002^{* * *}$ & $0.002^{* * *}$ \\
\hline & & $(0.000)$ & $(0.000)$ \\
\hline \multirow[t]{2}{*}{ Numeracy } & & & $2.713^{* * *}$ \\
\hline & & & $(0.485)$ \\
\hline \multirow[t]{2}{*}{ Hit15Index } & & & -0.332 \\
\hline & & & $(0.298)$ \\
\hline \multirow[t]{2}{*}{ constant } & $3.414^{* * *}$ & 1.025 & 1.132 \\
\hline & $(0.710)$ & $(0.956)$ & $(1.003)$ \\
\hline$R^{2}$ & 0.022 & 0.055 & 0.090 \\
\hline $\mathrm{N}$ & 1016 & 1014 & 884 \\
\hline
\end{tabular}

Table 14: Variables affecting choices over time, today vs. in 5 days. The dependent variable FuturePay.Acc. is the number of choices of the future payment over the earlier one. See the section 1.2 for a definition of the independent variables. 


\begin{tabular}{lccc}
\hline \hline & Future Pay. Acc. & Future Pay. Acc. & Future Pay. Acc. \\
& $\mathrm{b} / \mathrm{se}$ & $\mathrm{b} / \mathrm{se}$ & $\mathrm{b} / \mathrm{se}$ \\
\hline IQIndex & $2.356^{* * *}$ & $1.852^{* * *}$ & 0.825 \\
& $(0.575)$ & $(0.588)$ & $(0.716)$ \\
HarmAvoidance & -0.014 & -0.014 & -0.004 \\
& $(0.016)$ & $(0.016)$ & $(0.017)$ \\
YrsOfSchool & & $0.141^{* *}$ & $0.114^{*}$ \\
& & $(0.057)$ & $(0.060)$ \\
OppIncome & & 0.005 & 0.004 \\
& & $(0.006)$ & $(0.006)$ \\
ExperienceR & & 0.021 & 0.020 \\
& & $(0.050)$ & $(0.053)$ \\
LengthRJ & & -0.005 & -0.006 \\
& & $(0.010)$ & $(0.011)$ \\
CreditRisk & & $0.002^{* * *}$ & $0.002^{* * *}$ \\
& & $(0.000)$ & $(0.000)$ \\
Numeracy & & & $2.089^{* * *}$ \\
& & & $(0.519)$ \\
Hit15Index & & -0.204 & -0.149 \\
& & $(1.015)$ & $(0.318)$ \\
constant & & & -0.441 \\
& & & $(1.073)$ \\
\hline & & 0.052 & \\
$R^{2}$ & $0.755)$ & 1014 & 0.074 \\
N & & & 884 \\
\hline \hline
\end{tabular}

Table 15: Variables affecting choices over time, in 2 days vs. in 9 days. The dependent variable FuturePay.Acc. is the number of choices of the future payment over the earlier one. See the section 1.2 for a definition of the independent variables. 


\begin{tabular}{lccc}
\hline \hline & $\begin{array}{c}\text { Future Pay. Acc. } \\
\mathrm{b} / \mathrm{se}\end{array}$ & $\begin{array}{c}\text { Future Pay. Acc. } \\
\mathrm{b} / \mathrm{se}\end{array}$ & $\begin{array}{c}\text { Future Pay. Acc. } \\
\mathrm{b} / \mathrm{se}\end{array}$ \\
\hline IQIndex & $1.880^{* * *}$ & $1.423^{* *}$ & 0.361 \\
& $(0.585)$ & $(0.600)$ & $(0.738)$ \\
HarmAvoidance & $-0.034^{* *}$ & $-0.031^{*}$ & -0.019 \\
& $(0.017)$ & $(0.016)$ & $(0.018)$ \\
YrsOfSchool & & $0.163^{* * *}$ & $0.137^{* *}$ \\
& & $(0.059)$ & $(0.062)$ \\
OppIncome & & 0.009 & $0.011^{*}$ \\
& & $(0.006)$ & $(0.006)$ \\
ExperienceR & & 0.051 & 0.038 \\
& & $(0.051)$ & $(0.054)$ \\
LengthRJ & & -0.006 & -0.011 \\
& & $(0.010)$ & $(0.011)$ \\
CreditRisk & & $0.001^{* * *}$ & $0.001^{* *}$ \\
& & $(0.000)$ & $(0.000)$ \\
Numeracy & & & $1.721^{* * *}$ \\
Hit15Index & & & $(0.535)$ \\
& & & 0.247 \\
constant & & -0.361 & $(0.328)$ \\
& $\left(0.511^{* * *}\right.$ & $(1.036)$ & -0.698 \\
& & & $(1.106)$ \\
\hline \multirow{2}{*}{$R^{2}$} & 0.016 & 0.044 & 0.061 \\
$\mathrm{~N}$ & 1016 & 1014 & 884 \\
\hline \hline
\end{tabular}

Table 16: Variables affecting choices over time, in 2 days vs. in 30 days. The dependent variable FuturePay.Acc. is the number of choices of the future payment over the earlier one. See the section 1.2 for a definition of the independent variables. 


\section{Immediacy and IQ}

The dependent variable in the next regression is computed in two steps. First we determine the empirical correspondent of the present value to the subject of the future payment. This is the amount in dollars $x$ with the following property: a decision maker who is indifferent between the value $x$ paid at the earlier date and the value $\$ 80$ paid at the later day would have the same pattern of choice as the subject. The variable that we study is the log of the ratio between this $x$ for the subject and $\$ 80$. This is a measure of patience: the higher the value the more the subject is willing to postpone payments.

For each subject we have now 4 variables, each corresponding to one of the four choices over time. The regression below is the robust regression of the log of the ratio just defined on the set of independent variables indicated (with standard errors adjusted for the lack of independence among the observations on a particular subject).

\begin{tabular}{lcc}
\hline \hline & not immediate & immediate \\
& $\mathrm{b} / \mathrm{se}$ & $\mathrm{b} / \mathrm{se}$ \\
\hline $\mathrm{t}$ & $-0.004^{* * *}$ & $-0.017^{* * *}$ \\
& $(0.000)$ & $(0.001)$ \\
IQIndex & $0.184^{* * *}$ & $0.176^{* * *}$ \\
& $(0.045)$ & $(0.040)$ \\
constant & $-0.369^{* * *}$ & $-0.241^{* * *}$ \\
& $(0.037)$ & $(0.033)$ \\
\hline & & \\
$R^{2}$ & 0.042 & 0.048 \\
$\mathrm{~N}$ & 2032 & 2032 \\
\hline \hline
\end{tabular}

Table 17: The effect of IQ on time preferences is not affected by the presence of an immediate payment. The left column reports the regression for choices where the earlier payment is in two days, the right column for choices where the earlier payment is today. 


\section{Correlation among Preferences}

\subsection{Correlation among Preferences over Risk}

The next figure shows the lowess ([4]) scatter-plot of the coefficient of risk aversion for the lottery with lower stakes $(\$ 5, \$ 1)$ and the same coefficient for the lottery with higher stakes $(\$ 10, \$ 2)$. The two coefficients are clearly correlated.

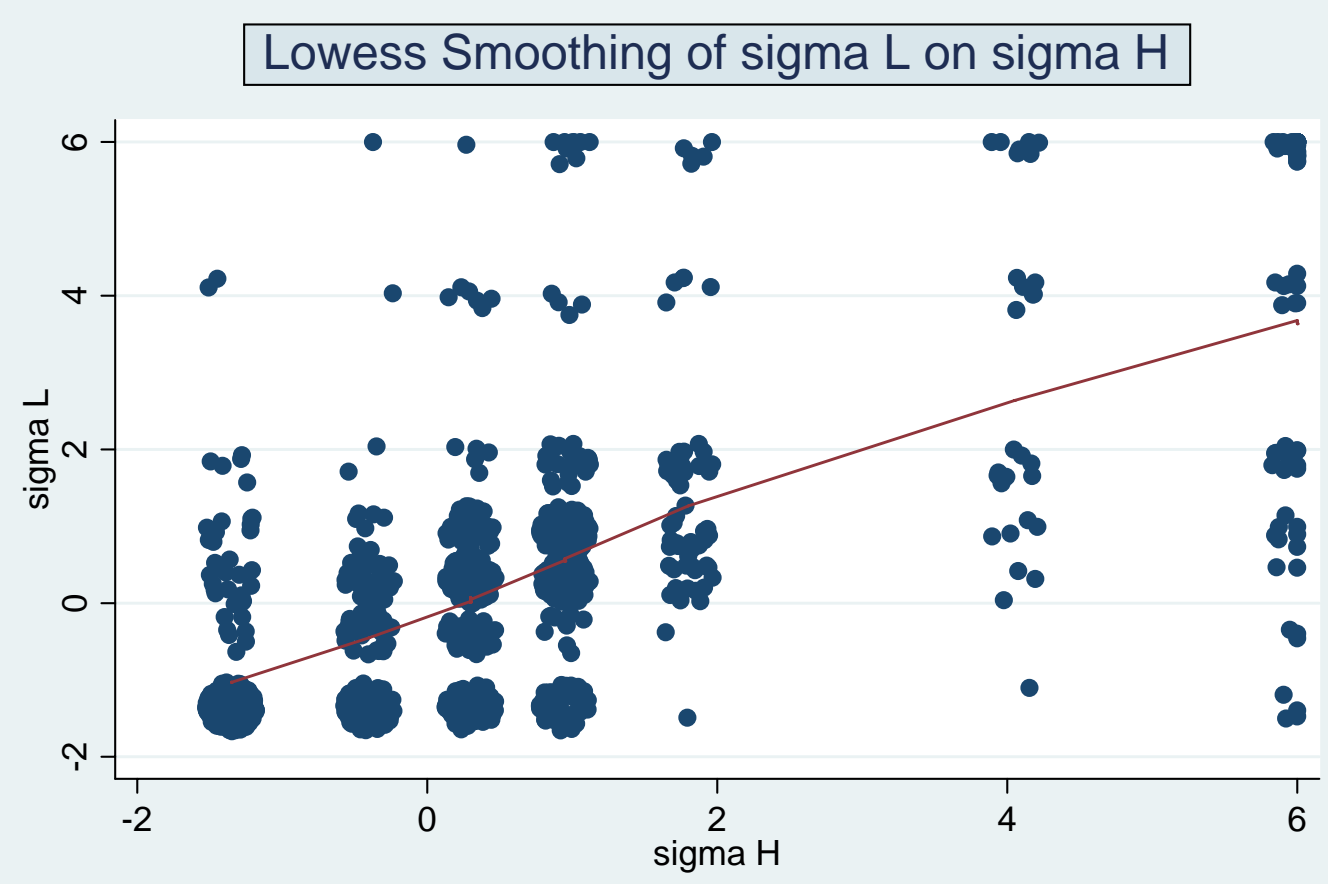

bandwidth $=.8$

Figure 2: The Two coefficients of Risk Aversion.

Since the coefficient for the lower stakes lottery is on average lower (as we have seen in Figure 2 of the main text) the scatter-plot shows that the data for the variable sigmaL are left censored. This suggests that the correct regression analysis of the relationship between the two variables is a tobit regression. The results of the standard and tobit regressions are diaplayed in the next table. 


\begin{tabular}{lcc}
\hline \hline & regression & tobit \\
$\sigma_{L}$ & $\mathrm{~b} / \mathrm{se}$ & $\mathrm{b} / \mathrm{se}$ \\
\hline$\sigma_{H}$ & $0.648^{* * *}$ & $0.998^{* * *}$ \\
& $(0.023)$ & $(0.042)$ \\
constant & $0.401^{* * *}$ & $-0.940^{* * *}$ \\
& $(0.042)$ & $(0.082)$ \\
\hline & & \\
& & \\
$R^{2}$ & 0.431 & 0.430 \\
$\mathrm{~N}$ & 1069 & 1069 \\
\hline \hline
\end{tabular}

Table 18: The Coefficients of Risk Aversion. $\sigma_{L}$ and $\sigma_{H}$ are the estimated coefficients of risk aversion in the Lower $(\$ 5, \$ 1)$ and Higher $(\$ 10, \$ 2)$ stakes lottery.

The tobit regression gives a coefficient of 1 between $\sigma_{L}$ and $\sigma_{H}$ : the coefficient of risk aversion for lower stakes is simply the translation of the one for the higher stakes by a -0.94 value. The $R^{2}$ reported for the tobit regression is the estimated one, not McFadden's pseudo- $R^{2}$.

The direct correlation between choices gives a similar result:

\begin{tabular}{lcc}
\hline \hline & regression & tobit \\
$R A A c c L$ & $\mathrm{~b} / \mathrm{se}$ & $\mathrm{b} / \mathrm{se}$ \\
\hline$R A A c c H$ & $0.689^{* * *}$ & $1.099^{* * *}$ \\
& $(0.024)$ & $(0.045)$ \\
constant & $1.571^{* * *}$ & $.59^{* * *}$ \\
& $(0.102)$ & $(0.175)$ \\
\hline & & \\
$R^{2}$ & 0.431 & 0.431 \\
$\mathrm{~N}$ & 1069 & 1069 \\
\hline \hline
\end{tabular}

Table 19: The Correlation among choices. $R A A c c H$ is the number of times the subject chooses the lottery instead of the certain amount in the higher stakes lottery; $R A A c c L$ is the same for the lower stakes lottery. 


\subsection{Correlation among Preferences over Time}

\begin{tabular}{lcc}
\hline \hline & regression & tobit \\
TPFut 1 & $\mathrm{~b} / \mathrm{se}$ & $\mathrm{b} / \mathrm{se}$ \\
\hline TPFut2 & $0.644^{* * *}$ & $1.275^{* * *}$ \\
& $(0.018)$ & $(0.051)$ \\
constant & $2.502^{* * *}$ & $1.217^{* * *}$ \\
& $(0.095)$ & $(0.207)$ \\
\hline & & \\
$R^{2}$ & 0.534 & .534 \\
$\mathrm{~N}$ & 1069 & 1069 \\
\hline \hline
\end{tabular}

Table 20: The Correlation among choices. TPFut1 is the number of times the subject chooses the future payment instead of the immediate payment in the first time choice (Today vs. Tomorrow); TPFut2 is the same for the second time choice (Today vs. in 5 days). 


\subsection{Correlation among Preferences in Different Domains}

The correlation among preferences in different domains (shown in Figure 2 of the test) may be due only to the common effect of the cognitive skills on the preferences, or, in addition to the effect of CS, there may also be a deeper relationship among the preferences. The regression results in Table 4.3 show that the second is a likely possibility. The regressions examine the possible correlation of risk and time preferences, once the effects of the IQ Index are taken into account.

\begin{tabular}{lcccc}
\hline \hline & TPFut1 & TPFut2 & TPFut3 & TPFut4 \\
& $\mathrm{b} / \mathrm{se}$ & $\mathrm{b} / \mathrm{se}$ & $\mathrm{b} / \mathrm{se}$ & $\mathrm{b} / \mathrm{se}$ \\
\hline RAAccPH & 0.055 & 0.052 & 0.056 & $0.118^{* *}$ \\
& $(0.041)$ & $(0.047)$ & $(0.050)$ & $(0.050)$ \\
IQ Index & $1.845^{* * *}$ & $2.416^{* * *}$ & $2.350^{* * *}$ & $1.885^{* * *}$ \\
& $(0.477)$ & $(0.540)$ & $(0.574)$ & $(0.583)$ \\
constant & $3.755^{* * *}$ & $2.437^{* * *}$ & $1.689^{* * *}$ & $0.917^{*}$ \\
& $(0.406)$ & $(0.461)$ & $(0.489)$ & $(0.497)$ \\
\hline & & & & \\
$R^{2}$ & 0.017 & 0.022 & 0.018 & 0.017 \\
$\mathrm{~N}$ & 1016 & 1016 & 1016 & 1016 \\
\hline \hline
\end{tabular}

Table 21: Regression of time choices over risk acceptance and IQ Index. The variables TPFuti, for $i=1, . ., 4$ and $R A A c c P H$ are as defined in Figure 2 of the text. 


\section{Strategic Behavior and Cognitive Skills}

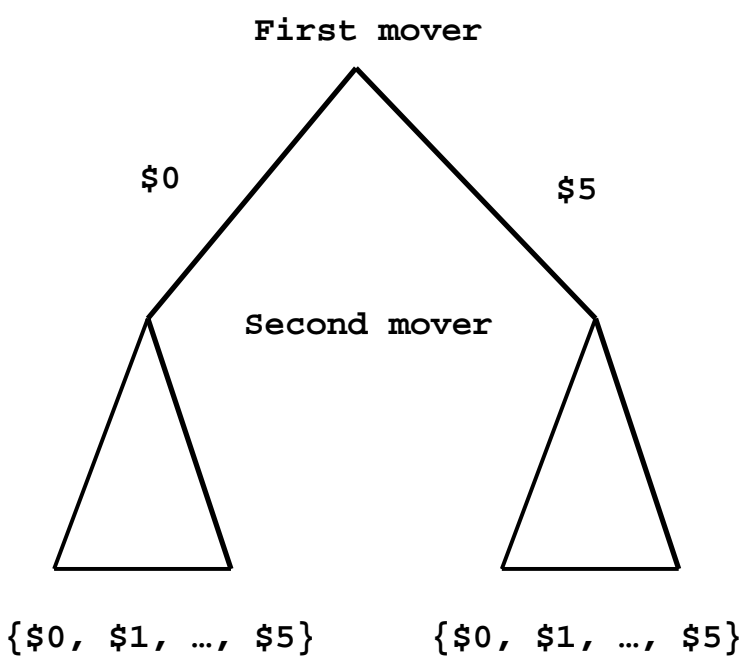

Figure 3: Description of the Game: There are two players, the first and second movers, who move in sequence. They are both endowed with $\$ 5$ by the experimenter. The first mover has to decide unconditionally whether to transfer $\$ 0$ or $\$ 5$ to the second mover. The second mover has to decide, before he knows the decision of the first mover, how much he would transfer back, with a separate decision for each of the two possible first mover actions. All amounts sent by either player are doubled by the experimenter. Subjects gave their decisions for both roles first, after which each subject was assigned one of the two roles at random, and was then randomly matched with another subject who was assigned to the opposite role. Subjects were paid according to the relevant choice each made, in the roles assigned. Subjects also had to report their beliefs about the likely choices of the other players in the room, and were paid for correctness of their guess. 


\subsection{Beliefs and Behavior in the Game}

\begin{tabular}{lcc}
\hline \hline & $\begin{array}{c}\text { Perc. Sending } \\
\mathrm{b} / \mathrm{se}\end{array}$ & $\begin{array}{c}\text { Perc. Sending } \\
\mathrm{b} / \mathrm{se}\end{array}$ \\
\hline IQ Index & $27.886^{* * *}$ & $21.658^{* * *}$ \\
& $(6.811)$ & $(7.910)$ \\
Numeracy & & 7.966 \\
& & $(5.155)$ \\
constant & $27.917^{* * *}$ & $27.293^{* * *}$ \\
& $(5.555)$ & $(5.566)$ \\
& & \\
\hline$R^{2}$ & 0.016 & 0.019 \\
$\mathrm{~N}$ & 1013 & 1013 \\
\hline \hline
\end{tabular}

Table 22: Beliefs of the first mover: Regression of the stated percentage of first movers sending $\$ 5$. 


\begin{tabular}{lcc}
\hline \hline & $\begin{array}{c}\text { Amount } \\
\mathrm{b} / \mathrm{se}\end{array}$ & $\begin{array}{c}\text { Amount } \\
\mathrm{b} / \mathrm{se}\end{array}$ \\
\hline IQ Index & $-2.011^{* * *}$ & $-1.323^{* *}$ \\
& $(0.450)$ & $(0.522)$ \\
Numeracy & & $-0.879^{* * *}$ \\
& & $(0.340)$ \\
constant & $3.329^{* * *}$ & $3.398^{* * * *}$ \\
& $(0.367)$ & $(0.367)$ \\
& & \\
\hline$R^{2}$ & 0.019 & 0.026 \\
$\mathrm{~N}$ & 1013 & 1013 \\
\hline \hline
\end{tabular}

Table 23: Beliefs of the second mover: Subject's estimate of the amount sent back after a transfer of $\$ 0$.

The independent variable is the answer to the following question: If Person 1 does send \$0, what is the average amount that participants in this room will send back? and the amount allowed was in units of 50 cents, for a total between $\$ 0$ and $\$ 5$. 


\begin{tabular}{lcc}
\hline \hline & $\begin{array}{c}\text { Amount } \\
\mathrm{b} / \mathrm{se}\end{array}$ & $\begin{array}{c}\text { Amount } \\
\mathrm{b} / \mathrm{se}\end{array}$ \\
\hline IQ Index & $1.275^{* * *}$ & $1.894^{* * *}$ \\
& $(0.474)$ & $(0.550)$ \\
Numeracy & & $-0.792^{* *}$ \\
& & $(0.359)$ \\
constant & $2.710^{* * *}$ & $2.772^{* * *}$ \\
& $(0.387)$ & $(0.387)$ \\
& & \\
\hline$R^{2}$ & 0.007 & 0.012 \\
$\mathrm{~N}$ & 1013 & 1013 \\
\hline \hline
\end{tabular}

Table 24: Beliefs of the second mover: Subject's estimate of the amount sent back after a transfer of $\$ 5$.

The independent variable is the answer to the following question: If Person 1 does send \$5, what is the average amount that participants in this room will send back? and the amount allowed was in units of 50 cents, for a total between $\$ 0$ and $\$ 5$. 


\begin{tabular}{lccc}
\hline \hline & $\begin{array}{c}\text { Distance } \\
\mathrm{b} / \mathrm{se}\end{array}$ & $\begin{array}{c}\text { Distance } \\
\mathrm{b} / \mathrm{se}\end{array}$ & $\begin{array}{c}\text { Distance } \\
\mathrm{b} / \mathrm{se}\end{array}$ \\
\hline IQ Index & $-14.039^{* * *}$ & $-10.732^{* *}$ & $-8.759^{*}$ \\
& $(4.232)$ & $(4.916)$ & $(5.264)$ \\
Numeracy & & -4.231 & -4.008 \\
& & $(3.204)$ & $(3.582)$ \\
Hit15 & & & -0.245 \\
& & & $(0.575)$ \\
constant & $40.414^{* * *}$ & $40.746^{* * *}$ & $39.449^{* * *}$ \\
& $(3.451)$ & $(3.459)$ & $(3.640)$ \\
& & & \\
\hline$R^{2}$ & 0.011 & 0.012 & 0.011 \\
$\mathrm{~N}$ & 1013 & 1013 & 884 \\
\hline \hline
\end{tabular}

Table 25: Beliefs of the first mover: Distance between the predicted and true frequency of subjects sending $\$ 5$ as first movers.

The variable Distance is the absolute value of the difference between the percentage of subjects sending $\$ 5$ as first movers and the true percentage, which is $67.07 \%$. 


\begin{tabular}{lccc}
\hline \hline & $\begin{array}{c}\text { Distance } \\
\mathrm{b} / \mathrm{se}\end{array}$ & $\begin{array}{c}\text { Distance } \\
\mathrm{b} / \mathrm{se}\end{array}$ & $\begin{array}{c}\text { Distance } \\
\mathrm{b} / \mathrm{se}\end{array}$ \\
\hline IQ Index & 0.122 & $0.641^{* *}$ & $0.460^{* *}$ \\
& $(0.277)$ & $(0.320)$ & $(0.230)$ \\
Numeracy & & $-0.664^{* * *}$ & -0.135 \\
& & $(0.209)$ & $(0.156)$ \\
Hit15 & & & -0.028 \\
& & & $(0.025)$ \\
constant & $1.496^{* * *}$ & $1.548^{* * *}$ & $1.201^{* * * *}$ \\
& $(0.226)$ & $(0.225)$ & $(0.159)$ \\
& & & \\
\hline$R^{2}$ & 0.000 & 0.010 & 0.005 \\
$\mathrm{~N}$ & 1013 & 1013 & 884 \\
\hline \hline
\end{tabular}

Table 26: Beliefs of the second mover: Distance between estimate and true mean in the $\$ 0$ transfer.

The variable Distance is the absolute value of the difference between the Amount estimated by the subject in the event of a $\$ 0$ transfer and then true mean, which is $\$ 1.698$. 


\begin{tabular}{lccc}
\hline \hline & $\begin{array}{c}\text { Distance } \\
\mathrm{b} / \mathrm{se}\end{array}$ & $\begin{array}{c}\text { Distance } \\
\mathrm{b} / \mathrm{se}\end{array}$ & $\begin{array}{c}\text { Distance } \\
\mathrm{b} / \mathrm{se}\end{array}$ \\
\hline IQ Index & $-0.502^{*}$ & 0.181 & -0.367 \\
& $(0.299)$ & $(0.345)$ & $(0.236)$ \\
Numeracy & & $-0.874^{* * *}$ & $-0.417^{* * *}$ \\
& & $(0.225)$ & $(0.161)$ \\
Hit15 & & & $0.056^{* *}$ \\
& & & $(0.026)$ \\
constant & $2.046^{* * *}$ & $2.115^{* * *}$ & $1.840^{* * * *}$ \\
& $(0.243)$ & $(0.242)$ & $(0.163)$ \\
& & & \\
\hline$R^{2}$ & 0.003 & 0.018 & 0.016 \\
$\mathrm{~N}$ & 1013 & 1013 & 884 \\
\hline \hline
\end{tabular}

Table 27: Beliefs of the second mover: Distance between estimate and true mean in the $\$ 5$ transfer.

The variable Distance is the absolute value of the difference between the Amount estimated by the subject in the event of a $\$ 0$ transfer and then true mean, which is $\$ 3.629$. 


\subsection{Behavior as First Mover}

\begin{tabular}{lcc}
\hline \hline & $\begin{array}{c}\text { Send } \$ 5 \\
\mathrm{~b} / \mathrm{se}\end{array}$ & $\begin{array}{c}\text { Send } \$ 5 \\
\mathrm{~b} / \mathrm{se}\end{array}$ \\
\hline diff & -0.021 & $-0.022^{* * *}$ \\
& $(0.017)$ & $(0.019)$ \\
$\mathrm{IQ}$ & $0.222^{* *}$ & $0.336^{* * *}$ \\
& $(0.115)$ & $(0.120)$ \\
diffIQ & $0.036^{*}$ & $0.039^{* * *}$ \\
& $(0.0218$ & $(0.022)$ \\
Age & & $0.006^{* * *}$ \\
& & $(0.0014)$ \\
RAAcc & & $0.008^{* *}$ \\
& & $(0.0027)$ \\
Male & & 0.0102 \\
& & $(0.049)$ \\
Credit Risk & & 0.001 \\
& & $(0.000)$ \\
Other Income & & -0.000 \\
& & $(0.000)$ \\
& & \\
\hline $\mathrm{N}$ & 884 & 881 \\
\hline \hline
\end{tabular}

Table 28: Logit regression on the decision to send the $\$ 5$ as first mover: Marginal effects of IQ.

The variable diff is the difference between the expected value of sending $\$ 5$ and sending $\$ 0$, computed according to the estimated quantity returned by the second mover that the subject has indicated in the elicitation of his beliefs. The variable $I Q$ is the IQ index. The variable diffIQ is the product of diff and $I Q$. 


\begin{tabular}{lcc}
\hline \hline & Send $\$ 5$ & Send $\$ 5$ \\
& $\mathrm{~b} / \mathrm{se}$ & $\mathrm{b} / \mathrm{se}$ \\
\hline diff & $0.013^{* * *}$ & $0.0014^{* * *}$ \\
& $(0.00389)$ & $(0.0039)$ \\
CSI & $0.061^{* * *}$ & $0.073^{* * *}$ \\
& $(0.023)$ & $(0.023)$ \\
diffCSI & $0.013^{* * *}$ & $0.012^{* * *}$ \\
& $(0.004)$ & $(0.0049)$ \\
Age & & $0.0073^{* * *}$ \\
& & $(0.001)$ \\
RAAcc & & $0.0065^{* *}$ \\
& & $(0.002)$ \\
Male & & 0.013 \\
& & $(0.059)$ \\
Credit Risk & & 0.0001 \\
& & $(0.00008)$ \\
Other Income & & -0.000 \\
& & $(0.000005)$ \\
& & \\
\hline $\mathrm{N}$ & 884 & 881 \\
\hline \hline
\end{tabular}

Table 29: Logit regression on the decision to send the $\$ 5$ as first mover: Marginal effects of the index of Cognitive Skill

The variable diff is the difference between the expected value of sending $\$ 5$ and sending $\$ 0$, computed according to the estimated quantity returned by the second mover that the subject has indicated in the elicitation of his beliefs. The variable CSI is the factor identified in the factor analysis of Cognitive Abilities. The variable diffCSI is the product of diff and CSI. 


\subsection{Behavior as Second Mover}

\begin{tabular}{|c|c|c|c|c|}
\hline & $\begin{array}{r}\text { Amount } \\
\mathrm{b} / \mathrm{se}\end{array}$ & $\begin{array}{r}\text { Amount } \\
\mathrm{b} / \mathrm{se}\end{array}$ & $\begin{array}{r}\text { Amount } \\
\mathrm{b} / \mathrm{se}\end{array}$ & $\begin{array}{r}\text { Amount } \\
\mathrm{b} / \mathrm{se}\end{array}$ \\
\hline IQ Index & $\begin{array}{l}-2.383^{* * *} \\
(0.453)\end{array}$ & $\begin{array}{l}-2.108^{* * *} \\
(0.526)\end{array}$ & $\begin{array}{l}-2.142^{* * *} \\
(0.563)\end{array}$ & $\begin{array}{l}-1.800^{* * *} \\
(0.577)\end{array}$ \\
\hline Numeracy & & $\begin{array}{l}-0.351 \\
(0.343)\end{array}$ & $\begin{array}{r}0.192 \\
(0.383)\end{array}$ & $\begin{array}{r}0.038 \\
(0.393)\end{array}$ \\
\hline Hit15Index & & & $\begin{array}{l}-0.582^{* *} \\
(0.246)\end{array}$ & $\begin{array}{l}-0.387 \\
(0.252)\end{array}$ \\
\hline Age & & & & $\begin{array}{l}0.021^{* * * *} \\
(0.007)\end{array}$ \\
\hline RAAcc & & & & $\begin{array}{l}0.041^{* * * *} \\
(0.012)\end{array}$ \\
\hline Male & & & & $\begin{array}{l}-0.291 \\
(0.212)\end{array}$ \\
\hline Credit Risk & & & & $\begin{array}{l}-0.000 \\
(0.000)\end{array}$ \\
\hline Other Income & & & & $\begin{array}{r}0.000 \\
(0.000)\end{array}$ \\
\hline constant & $\begin{array}{l}3.634^{* * * *} \\
(0.369)\end{array}$ & $\begin{array}{l}3.662^{* * *} \\
(0.370)\end{array}$ & $\begin{array}{l}3.622^{* * * *} \\
(0.390)\end{array}$ & $\begin{array}{l}2.316^{* * * *} \\
(0.587)\end{array}$ \\
\hline$R^{2}$ & 0.027 & 0.028 & 0.037 & 0.063 \\
\hline $\mathrm{N}$ & 1013 & 1013 & 884 & 881 \\
\hline
\end{tabular}

Table 30: Behavior as Second Mover, After a $\$ 0$ transfer.

The variable Amount is the monetary amount that the subject decides to send back to the first mover if he transferred $\$ 0$. 


\begin{tabular}{|c|c|c|c|c|}
\hline & $\begin{array}{l}\text { Amount } \\
\mathrm{b} / \mathrm{se}\end{array}$ & $\begin{array}{r}\text { Amount } \\
\mathrm{b} / \mathrm{se}\end{array}$ & $\begin{array}{r}\text { Amount } \\
\mathrm{b} / \mathrm{se}\end{array}$ & $\begin{array}{r}\text { Amount } \\
\mathrm{b} / \mathrm{se}\end{array}$ \\
\hline IQ Index & $\begin{array}{l}1.321^{\text {*** }} \\
(0.423)\end{array}$ & $\begin{array}{c}0.829^{*} \\
(0.490)\end{array}$ & $\begin{array}{r}0.758 \\
(0.526)\end{array}$ & $\begin{array}{l}1.068^{* *} \\
(0.542)\end{array}$ \\
\hline Numeracy & & $\begin{array}{l}0.630^{* *} \\
(0.320)\end{array}$ & $\begin{array}{c}0.853^{* *} \\
(0.358)\end{array}$ & $\begin{array}{c}0.725^{* *} \\
(0.369)\end{array}$ \\
\hline Hit15Index & & & $\begin{array}{c}-0.092 \\
(0.230)\end{array}$ & $\begin{array}{l}-0.080 \\
(0.237)\end{array}$ \\
\hline Age & & & & $\begin{array}{r}0.010 \\
(0.006)\end{array}$ \\
\hline RAAcc & & & & $\begin{array}{l}0.027^{* *} \\
(0.011)\end{array}$ \\
\hline Male & & & & $\begin{array}{r}0.255 \\
(0.199)\end{array}$ \\
\hline Credit Risk & & & & $\begin{array}{r}0.000 \\
(0.000)\end{array}$ \\
\hline Other Income & & & & $\begin{array}{c}0.000^{*} \\
(0.000)\end{array}$ \\
\hline constant & $\begin{array}{l}2.569^{* * * *} \\
(0.345)\end{array}$ & $\begin{array}{l}2.520^{* * *} \\
(0.345)\end{array}$ & $\begin{array}{l}2.486^{* * * *} \\
(0.364)\end{array}$ & $\begin{array}{c}1.006^{*} \\
(0.551)\end{array}$ \\
\hline$R^{2}$ & 0.010 & 0.013 & 0.016 & 0.034 \\
\hline $\mathrm{N}$ & 1013 & 1013 & 884 & 881 \\
\hline
\end{tabular}

Table 31: Behavior as Second Mover, After a $\$ 5$ transfer.

The variable Amount is the monetary amount that the subject decides to send back to the first mover if he transferred $\$ 5$. 


\section{Analysis of Exits from the Company}

Of the 1069 subjects that participated in the study, a total of 653 had left the company by $4 / 07 / 2007$. The table below presents a breakdown of the total exits in three different ways, depending on whether the exit was voluntary or not, whether it was before or after completion of training, and on whether the worker gave notice of the exit. The final group, MIAQuit, are the "Missing in Action" drivers who left the company without notice.

\begin{tabular}{llc}
\hline \hline Name of the Variable & Description & Number \\
\hline AllExits & all exits at any time for any reason & 653 \\
\hline Discharge & all involuntary exits, at any time & 162 \\
VolQuit & all voluntary exits, at any time & 491 \\
\hline JobExit & all on-the-job exits, for any reason & 539 \\
TrngExit & all in-training exits, for any reason & 114 \\
\hline MIAQuit & all those who left without notice, at any time & 142 \\
\hline \hline
\end{tabular}

Table 32: Reasons for exits from the job or training out of the total 1069 participants. The numbers are as of 4/07/2007.

\subsection{Empirical Estimates of the Survival rate}

The hazard rate $h(t)$ is as usual the ratio of the instantaneous failure rate $f(t)$ and the survival rate $S(t)$ :

$$
h(t)=\frac{f(t)}{S(t)}
$$

The empirical estimate of the survival rate $S(t)$ used in the Figures in the test is the Kaplan-Mayer estimator ([9]).

The estimated hazard rate for a subject with a vector of independent variables $x$ is assumed to be, following the Cox proportional hazard model,

$$
h(t \mid x)=h_{0}(t) \exp (\beta \cdot x)
$$

The baseline hazard $h_{0}(t)$ is common to all subjects. The vector of parameters $\beta$ is estimated and indicates the effect of the individual values of the variables $x$. The estimated effects of each independent variable shift the baseline hazard up or down, so a hazard rate larger than 1 indicates an increase of the hazard rate with respect to the baseline, a rate equal to 1 means no effect, and a rate strictly less than 1 indicates a reduction of the hazard rate with respect to the baseline.

As noted in the test, the Kaplan Meyer survival rates show that survival is increasing in the cognitive skill scores. The single exception is the group in the top quintile of the Numeracy scale: individuals in this group have a survival rate smaller than the next lower group. It is natural to imagine that a very high score 
in numeracy makes it convenient for the driver to look for a different, perhaps more qualified, occupation, hance it may induce quitting. To keep into account the nonmonotonic effect of numeracy, in the regressions below we introduce each quintile in Numeracy as a separate regressor. The non monotonic effect is confirmed: the survival rate of all numeracy quintiles have a higher hazard rate (lower survival) then the fourth.

\subsection{Early and Late Exits}

\begin{tabular}{lrrrr}
\hline \hline Variable & Haz. Ratio & St. Err. & $z$ & $p$-value \\
\hline Hit15Index & 0.572 & 0.095 & -3.35 & 0.001 \\
IQ Index & 0.547 & 0.198 & -1.67 & 0.095 \\
NumQuint1 & 1.418 & 0.256 & 1.94 & 0.053 \\
NumQuint2 & 1.431 & 0.230 & 2.23 & 0.026 \\
NumQuint3 & 1.349 & 0.202 & 2 & 0.046 \\
NumQuint5 & 1.490 & 0.288 & 2.06 & 0.039 \\
Age & 1.003 & 0.005 & 0.6 & 0.549 \\
Married & 0.944 & 0.087 & -0.63 & 0.527 \\
Male & 1.009 & 0.141 & 0.06 & 0.951 \\
RAAcc & 0.992 & 0.009 & -0.84 & 0.398 \\
AAAcc & 1.006 & 0.009 & 0.65 & 0.513 \\
TPFut & 0.996 & 0.005 & -0.69 & 0.489 \\
CreditRisk & 1.000 & 0.000 & -0.29 & 0.775 \\
ExperienceR & 0.964 & 0.027 & -1.34 & 0.179 \\
\hline
\end{tabular}

Table 33: Hazard ratio for All Exits (AllExits): Cognitive Skills, Demographic and Socioeconomic variables. $R A A c c$ is the total number of times the subject chooses the lottery in the Risky choice, and $A A A c c$ the same for the Ambiguous choices. TPFut is the total number of times the subject chooses the further payment. CreditRisk is the Credit score of the driver. Experience $R$ is the length of previous experience in on-road driving. 


\begin{tabular}{lrrrr}
\hline \hline Variable & Haz. Ratio & St. Err. & $z$ & $p$-value \\
\hline Hit15Index & 0.350 & 0.126 & -2.92 & 0.004 \\
IQIndex & 0.536 & 0.381 & -0.88 & 0.38 \\
NumQuint1 & 2.438 & 1.161 & 1.87 & 0.061 \\
NumQuint2 & 2.325 & 1.042 & 1.88 & 0.06 \\
NumQuint3 & 1.826 & 0.797 & 1.38 & 0.168 \\
NumQuint5 & 2.272 & 1.149 & 1.62 & 0.105 \\
Age & 1.040 & 0.010 & 4.08 & 0.0001 \\
Married & 0.823 & 0.161 & -1 & 0.319 \\
Male & 0.919 & 0.247 & -0.31 & 0.753 \\
RAAcc & 0.984 & 0.019 & -0.84 & 0.403 \\
AAAcc & 0.998 & 0.015 & -0.1 & 0.918 \\
TPFut & 0.990 & 0.010 & -0.95 & 0.34 \\
CreditRisk & 1.000 & 0.000 & 0.68 & 0.498 \\
ExperienceR & 0.813 & 0.049 & -3.44 & 0.001 \\
\hline
\end{tabular}

Table 34: Hazard ratio for Exits during Training (TrngExit): Cognitive Skills, Demographic and Socioeconomic variables. 


\begin{tabular}{lrrrr}
\hline \hline Variable & Haz. Ratio & St. Err. & $z$ & $p$-value \\
\hline Hit15Index & 0.640 & 0.120 & -2.39 & 0.017 \\
IQIndex & 0.548 & 0.217 & -1.52 & 0.129 \\
NumQuint1 & 1.320 & 0.259 & 1.41 & 0.158 \\
NumQuint2 & 1.342 & 0.233 & 1.7 & 0.09 \\
NumQuint3 & 1.308 & 0.212 & 1.66 & 0.097 \\
NumQuint5 & 1.419 & 0.301 & 1.65 & 0.099 \\
Age & 0.993 & 0.006 & -1.18 & 0.237 \\
Married & 0.980 & 0.099 & -0.2 & 0.844 \\
Male & 1.029 & 0.161 & 0.19 & 0.853 \\
RAAcc & 0.994 & 0.010 & -0.57 & 0.569 \\
AAAcc & 1.007 & 0.010 & 0.73 & 0.465 \\
TPFut & 0.998 & 0.006 & -0.34 & 0.736 \\
CreditRisk & 1.000 & 0.000 & -0.47 & 0.64 \\
ExperienceR & 1.003 & 0.031 & 0.1 & 0.919 \\
\hline
\end{tabular}

Table 35: Hazard ratio for Exits on the Job (JobExit): Cognitive Skills, Demographic and Socioeconomic variables. 


\section{References}

[1] Baltagi, B. H., (2001), Econometric Analysis of Panel Data, New York, Wiley

[2] Burks, S., Carpenter, J. and Gtte, L. (2006), "Performance Pay and the Erosion of Worker Cooperation: Field Experimental Evidence", Discussion Paper \#2013, Bonn, Institute for the Study of Labor (IZA)

[3] Burks S, Carpenter J, Gotte L, Monaco K, Porter K, et al. (2008) in The Analysis of Firms and Employees: Quantitative and Qualitative Approaches, eds. Bender S, Lane J, Shaw K, Andersson F, \& von Wachter T (NBER and University of Chicago)

[4] Cleveland, W.S., (1979) "Robust Locally Weighted Regression and Smoothing Scatterplots", Journal of the American Statistical Association, December, Vol, 74, No. 368, 829-836

[5] Cox, D. R., (1972), "Regression models and life tables", Journal of the Royal Statistical Society, B34:187-220

[6] Cox, D. R. and Oakes D., (1984), Analysis of survival data, London: Chapman and Hall

[7] Gneezy, U., Rustichini, A. and Vostroknutov, A., (2007), "Backward Induction as a cognitive Process", mimeo

[8] Kahneman, D. and Tversy, A., (1979), "Prospect Theory: An Analysis of Decision under Risk", Econometrica, 47, 2, 263-292

[9] Kaplan E.L. and Meier P., (1958), "Nonparametric estimation from incomplete observations", Journal of the American Statistical Association, 53: 457-481

[10] Laibson, D., (1997). Golden eggs and hyperbolic discounting. Quarterly Journal of Economics, 112, 443-477.

[11] Maccheroni, F., Marinacci, M., and Rustichini, A., (2006), "Ambiguity Aversion, Robustness, and the Variational Representation of Preferences", Econometrica, November, 1-62

[12] Patrick, C., Curtin, J., and Tellegan, A., (2002), "Development and Validation of a Brief Form of the Multidimensional Personality Questionnaire", Psychological Assessment, Vol. 14, No. 2, 150-163

[13] Pollack, and Phelps, E, (1968). On Second-Best National Savings and GameEquilibrium Growth. The Review of Economic Studies, 35, 2, 185-199.

[14] Raven, J.C., (2000), Ravens Standard Progressive Matrices (SPM) and Ravens Standard Progressive Matrices Plus (SPM Plus), Pearson. 